\title{
Research on the Strength Characteristics and Crack Propagation Law of Noncoplanar Nonthrough Jointed Rock Mass by PFC2D
}

\author{
Qingzhi Chen $\mathbb{D}^{1},{ }^{1}$ Yuanming Liu $\mathbb{D}^{\circ},{ }^{1}$ Shilong Mei, ${ }^{2}$ Kai Cao, ${ }^{3}$ Bin Du, ${ }^{4}$ and Wei Wang ${ }^{5}$ \\ ${ }^{1}$ College of Civil Engineering, Guizhou University, Guiyang 550025, Guizhou, China \\ ${ }^{2}$ College of Architecture and Urban Planning, Guizhou University, Guiyang 550025, Guizhou, China \\ ${ }^{3}$ Guiyang Vocational and Technical College, Guiyang 550000, Guizhou, China \\ ${ }^{4}$ Guizhou Transportation Planning Survey Design \& Research Institute Co., Ltd., Guiyang 550000, Guizhou, China \\ ${ }^{5}$ General Construction Co.of CCTEB Group Co., Ltd., Wuhan 430064, Hubei, China \\ Correspondence should be addressed to Qingzhi Chen; 1064174907@qq.com and Yuanming Liu; 845612605@qq.com
}

Received 2 May 2021; Revised 8 June 2021; Accepted 22 July 2021; Published 3 August 2021

Academic Editor: Chunyang Zhang

Copyright $\odot 2021$ Qingzhi Chen et al. This is an open access article distributed under the Creative Commons Attribution License, which permits unrestricted use, distribution, and reproduction in any medium, provided the original work is properly cited.

\begin{abstract}
In this study, five groups of numerical models with different conditions were established by using PFC2D (particle flow code) to simulate the direct shear tests of noncoplanar nonthrough jointed rock mass. It is proved that normal stress and shear rate, as well as the connectivity rate, relief angle, and inclination angle of joints, have significant influence on the strength characteristics, number of cracks, and the stress of the rock mass according to measurement taken at five different measurement circles in the rock mass. Moreover, it is determined that in the process of shearing, no matter which group of tests are conducted, the number of cracks in the rock mass caused by tension is far more than that caused by the shear action. In other words, the failure of rock mass with different planes and discontinuous joints is mainly caused by the tension in the process of the direct shear test.
\end{abstract}

\section{Introduction}

A rock mass is a complex geological body with obvious nonlinearity, discontinuity, heterogeneity, and anisotropy. Within a rock mass, there can be joints, cracks, bedding, schistosity, faults, folds, and other structural planes [1-4]. All these different types of structures are collectively referred to as joints, and a rock mass containing various joints is termed as the jointed rock mass. The existence of joints makes the mechanical properties of a jointed rock mass to differ greatly from those of an intact rock [5-9]. The jointed rock mass is the most common complex engineering medium in construction engineering, water conservancy and hydropower engineering, underground space engineering, mineral resource exploration and development engineering, transportation engineering, bridge and tunnel engineering, oil port engineering, and other projects. Its strength and extended through characteristics play a vital role in construction in civil engineering. The mechanical properties of the jointed rock mass are important factors that must be considered in the analysis, evaluation, and design of rock engineering. The existence of joints makes the stability and safety of the built underground engineering projects to have great hidden dangers [10-12]. In addition, with the development of large engineering projects in recent years, the number, scale, difficulty, and complexity of rock mass engineering during the construction period have increased significantly, and the problems in rock mechanics in the construction process have become more complex. These mechanical problems of jointed rock mass will directly increase the technical difficulty of construction and affect the quality and cost of the project [13-15]. If the problems cannot be handled well, it will even cause casualties and serious losses due to the destruction of the complex rock mass. In order to facilitate the study, and based on whether the internal joint plane of the rock mass is through and the degree of joint opening or closing, a jointed rock mass is divided into two types: a through jointed rock mass and a nonthrough jointed rock mass [16-20]. On the basis of the spatial arrangement of rock masses and joints, or whether 
the joint surface and shear plane are on the same plane, the nonthrough jointed rock mass can be further divided into coplanar nonthrough jointed rock mass (CNJRM) and noncoplanar nonthrough jointed rock mass (NNJRM) [21]. The schematics of CNJRM and NNJRM are shown in Figures 1 and 2, respectively. In this study, numerical simulation experiments are carried out to study the law of crack propagation and the strength characteristics of rock mass in the process of the direct shear test.

The physical model test or numerical simulation test is widely used in the study of nonthrough jointed rock mass. This is because it can be quite difficult and costly to conduct the test in the field or by using natural rock specimens. In addition, the test repeatability will be poor, and the difference between individual and overall measurements would be greater, and so would the error of the test result. However, since the physical model test is greatly affected by the machinery used in the test and the operation mode of the operator in the experimental process, the accuracy of the experimental results has certain discreteness. Moreover, the cost of the physical model test is higher than that of the numerical simulation test. Therefore, if the parameters of the simulated material can be determined, many experts and scholars tend to use the numerical simulation test to study the mechanical properties of the incoherent jointed rock mass [22-29].

There are a variety of simulation programs for performing numerical simulation tests, among which the PFC2D (particle flow code) for particle discrete element analysis developed by ITASCA has been widely used [30-34]. This program studies the mechanical properties of the medium from the perspective of microstructure, which is very suitable for the in-depth study of high-level topics such as the expansion, fracture, failure, failure impact, and microseismic response of meso- or macrojoints in solid materials. At present, many experts and scholars have shown that the simulation test results of the PFC program are stable and reliable. For example, Zhou et al. [35] simulated the direct shear test of nontransfixion jointed rock mass based on the particle discrete element theory and the PFC2D program, and also analyzed the mechanical properties and breaking mechanism of joints in experiments from both the macro- and microaspects. The results of the simulation test were compared with the results of the indoor model test, and it was found that the new particle flow calculation method is very suitable for the simulation test of nonthrough jointed rock mass. This method has high reliability and thus can provide good reference for direct shear test of jointed rock mass in the laboratory and also for parameter selection when using PFC to simulate the joint model. Zhou et al. [36, 37] also took the natural slope as the research background and used the granular model and smooth joint model to simulate a rock block and joint, respectively, based on the particle discrete element theory and by using the PFC2D numerical simulation program. By repeatedly comparing and debugging the test results of the uniaxial compression test, direct shear test, and numerical test, the micromechanical parameters of the granular model and smooth joint model were determined. In

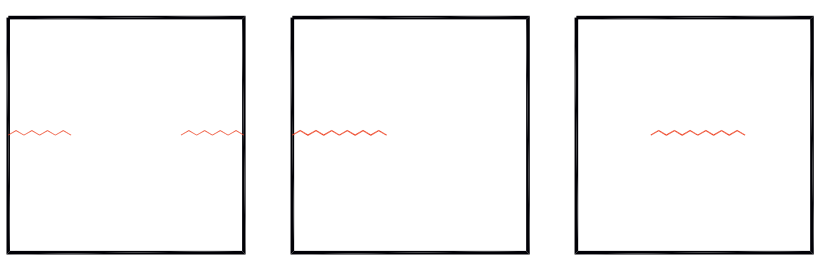

Figure 1: The schematic diagram of CNJRM.

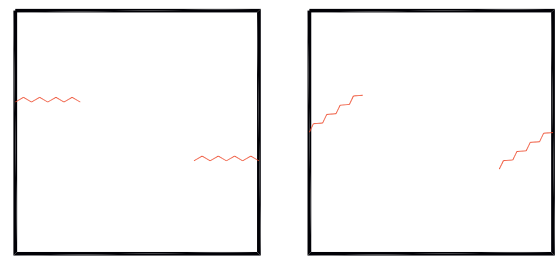

FIgURE 2: The schematic diagram of NNJRM.

addition, the mesoanalysis model of the intermittent jointed rock slope was established successfully. From the mesoscopic point of view, they successfully studied the mechanical properties of the rock mass model with two discontinuous joints and the bedding rock slope model with discontinuous joints in the failure process. Yang et al. [38] used the PFC3D program to study the effect of joint direction on the strength, deformation, and failure mode of joint blocks. Wang et al. [39] used the PFC3D program to establish the experimental model of coal gangue with different particle sizes, and simulated the triaxial compression test based on the model. By comparing the stressstrain curve, volume strain curve, and microcrack development curve under different confining pressures, he studied the strength characteristics and deformation law of coal gangue with different particle sizes. Hu et al. [40] used the PFC program to establish a rock slope model containing nonpenetrating jointed rock mass, and calculated the relevant mechanical parameters of the rock mass through simulated direct shear test, biaxial test, Brazil split test, and other conventional mechanical tests, so as to study various failure modes of the rock slope and its internal mesoscopic mechanism during the failure of the rock slope. In addition, many experts, including Huan et al. [41], Jiang et al. [42], Regassa et al. [43], Liu et al. [44], Cao et al. [45], Ghazvinian et al. [46], and Tao et al. [47], have used the PFC program or DEM (discrete element method) program to study various properties of rock masses.

Therefore, the PFC2D program was also used in this study to simulate the direct shear test, so as to investigate the influence of the undulating angle, inclination angle, joint connectivity rate, normal stress, and shear rate on the transfixion mechanism, strength, and deformation characteristics of NNJRM. By studying the stress-strain development state of the specimen as a whole based on the data collected from five measurement points inside the specimen (as shown in Figure 3) during the test, and the change in the number of cracks in the specimen during the test process, the mechanical properties of the nonpenetrating jointed rock mass under different working conditions were investigated. 


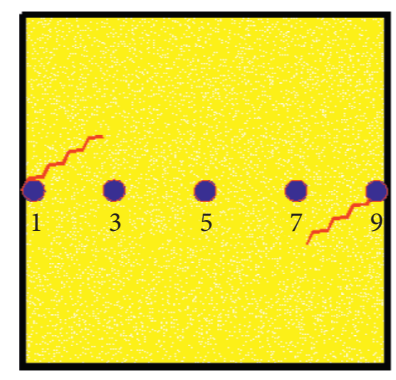

FIgURE 3: The positions of the five measurement circles.

It needs to be explained that the joint relief angle of the noncoplanar nonthrough jointed rock mass, represented by $i$, refers to the unevenness of a single structural plane in the joint relative to the whole joint, as shown in Figure 4. The joint inclination angle, represented by $\phi$, refers to the inclined angle between the joint tendency and the stress direction of the rock mass [21], as shown in Figure 5. The joint connectivity of the noncoplanar nonthrough jointed rock mass, represented by $j$, is defined as the ratio of the sum of the projection lengths of each joint segment in the direction of the shear plane to the length of the survey line. Its calculation formula is $j=2 S / L$. The numerical model established in this study adopts $L$ as a fixed value, $L=200 \mathrm{~mm}$. The joint connectivity of the rock mass with different plane joints is shown in Figure 6.

\section{Numerical Simulation Test Scheme for NNJRM}

2.1. Establishment of Model. In the numerical simulation part of this study, PFC2D was used to investigate and analyze the NNJRM. The establishment process of the test model is as follows: (1) six walls were defined to form a rectangular range of $200 \mathrm{~mm} \times 200 \mathrm{~mm}$, (2) relevant mesomechanical parameters were calibrated, and the particles were randomly generated and the suspended ones were eliminated (a total of 9356 effective spherical particles were generated inside the wall), (3) joints with connectivity, undulation, and inclination were introduced into the model to form the NNJRM, (4) direct shear test was conducted through FISH language simulation, and (5) five measuring circles were introduced to measure the level of stress (the five measuring circles are shown in Figure 3). The entire modeling process is illustrated in Figure 7.

2.2. Selection of Microscopic Mechanical Parameters. It should be noted that the calibration of mesomechanical parameters is the core of the model establishment process. It is only when these parameters are set accurately can the test results obtained by the numerical simulation test be true and reliable and can the numerical model be applied to the study of the mechanical properties of NNJRM. The specific method of parameter calibration is as follows: a group of parameters, which can make the numerical simulation test results to match with the experimental results of the physical model test, was obtained through multiple preassignment of

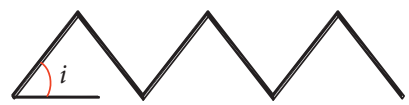

Figure 4: The schematic diagram of the joint relief angle.

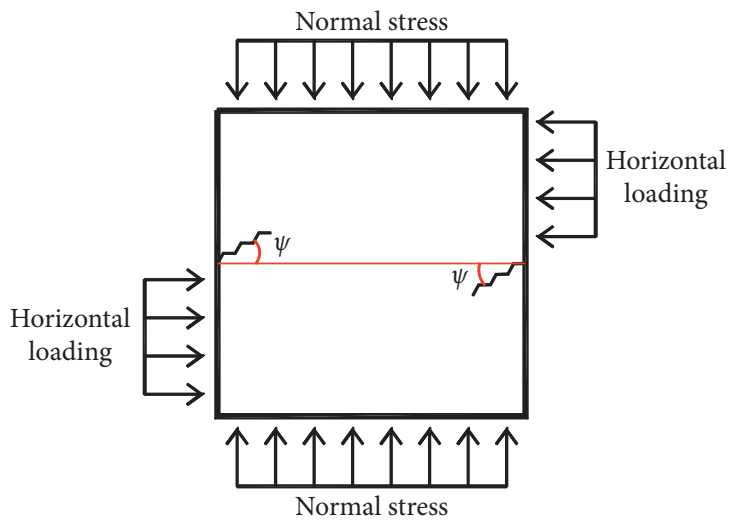

FIgURE 5: The loading mode and the joint inclination angle of NNJRM.

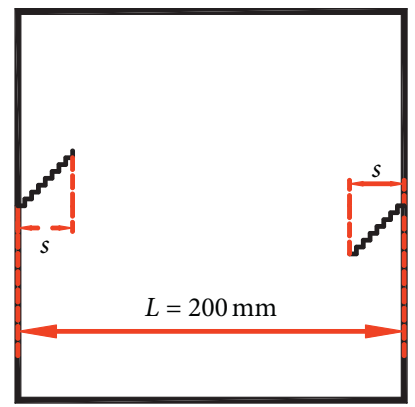

FIgURE 6: The joint connectivity of NNJRM.

micromechanical parameters such as the adhesion stiffness, bond strength, particle density, particle radius, elastic modulus of particles, and Poisson's ratio between particles and walls. Since a set of parameters that meet the requirements were already determined in previous studies $[27,28]$, the calibration process of the parameters was not repeated here. The set of parameters used in this model is shown in Table 1.

2.3. Description of the Test Conditions. The numerical simulation tests of a rock mass with different discontinuity joints under different working conditions are divided into five groups, as shown in Table 2.

2.3.1. Group 1: Simulation Test of NNJRM under Different Normal Stresses. When the shear rate is $0.06 \mathrm{~mm} / \mathrm{s}$, the numerical simulation tests with normal stresses of $0.5 \mathrm{mpa}$, $1.0 \mathrm{MPa}, 1.5 \mathrm{mpa}, 2.0 \mathrm{mpa}$, and $3.0 \mathrm{mpa}$ were carried out for the NNJRM with a joint relief angle of $15^{\circ}$, inclination angle of $15^{\circ}$, and connectivity rate of 0.5 . 


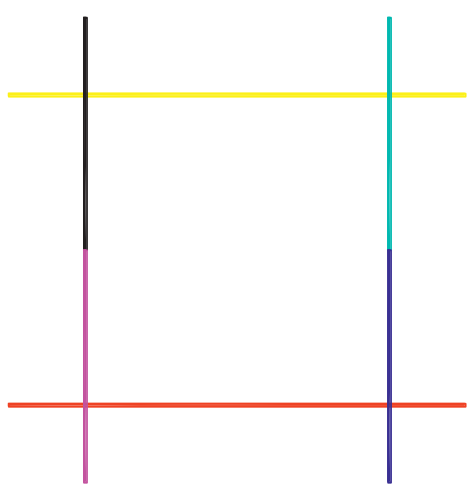

(a)

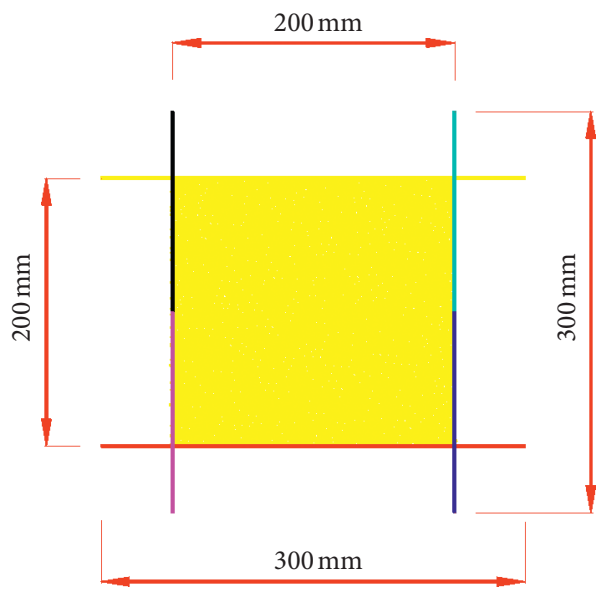

(c)

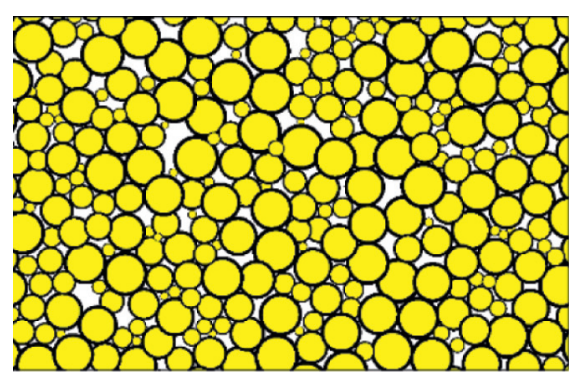

(b)

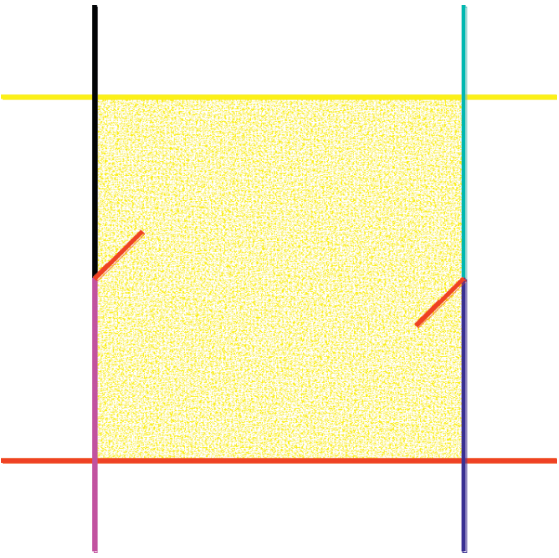

(d)

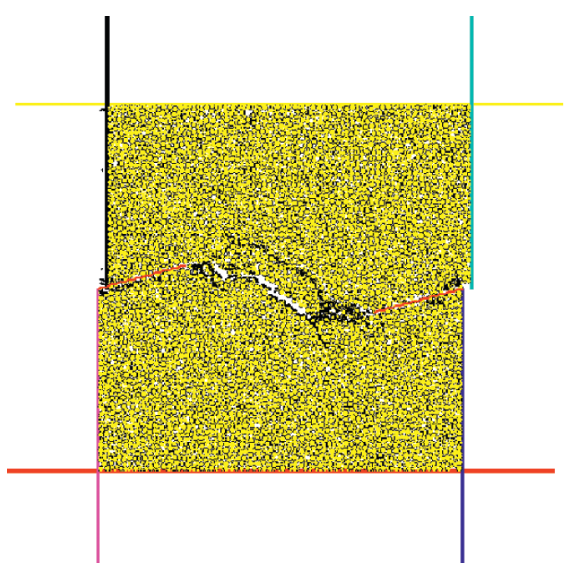

(e)

Figure 7: The model establishment process. (a) The range of 6-wall forming models. (b) Spherical particles formed in the wall. (c) The sample model after sphere stabilization. (d) The model after importing the different joints. (e) The model after the direct shear test.

2.3.2. Group 2: Simulation Test of NNJRM with Different Connectivity Rates. When the shear rate is $0.06 \mathrm{~mm} / \mathrm{s}$, the numerical simulation tests with a normal stress of $1.0 \mathrm{MPa}$ were carried out for the NNJRM with a joint relief angle of $15^{\circ}$, inclination angle of $15^{\circ}$, and connectivity rates of $0.1,0.2$, $0.3,0.4$, and 0.5 , successively. Rate States. When the normal stress is $1.0 \mathrm{MPa}$, the numerical simulation tests with horizontal shear rates of $0.02 \mathrm{~mm} / \mathrm{s}, 0.04 \mathrm{~mm} / \mathrm{s}, 0.06 \mathrm{~mm} / \mathrm{s}, 0.08 \mathrm{~mm} / \mathrm{s}$, and $0.10 \mathrm{~mm} /$ $s$ were carried out for the NNJRM with a joint relief angle of $15^{\circ}$, inclination angle of $15^{\circ}$, and connectivity rate of 0.5 .

2.3.4. Group 4: Simulation Test of NNJRM with Different Joint Relief Angles. When the shear rate is $0.06 \mathrm{~mm} / \mathrm{s}$ and the normal stress is $1.0 \mathrm{MPa}$, the numerical simulation tests were carried out for the NNJRM with joint inclination angle of 


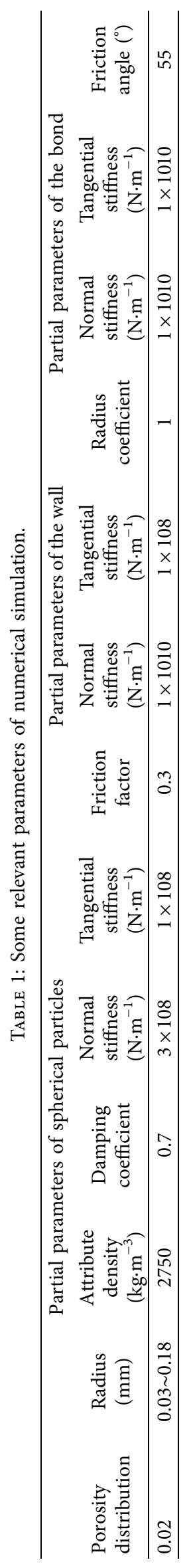


TABLE 2: Grouping of numerical simulation tests.

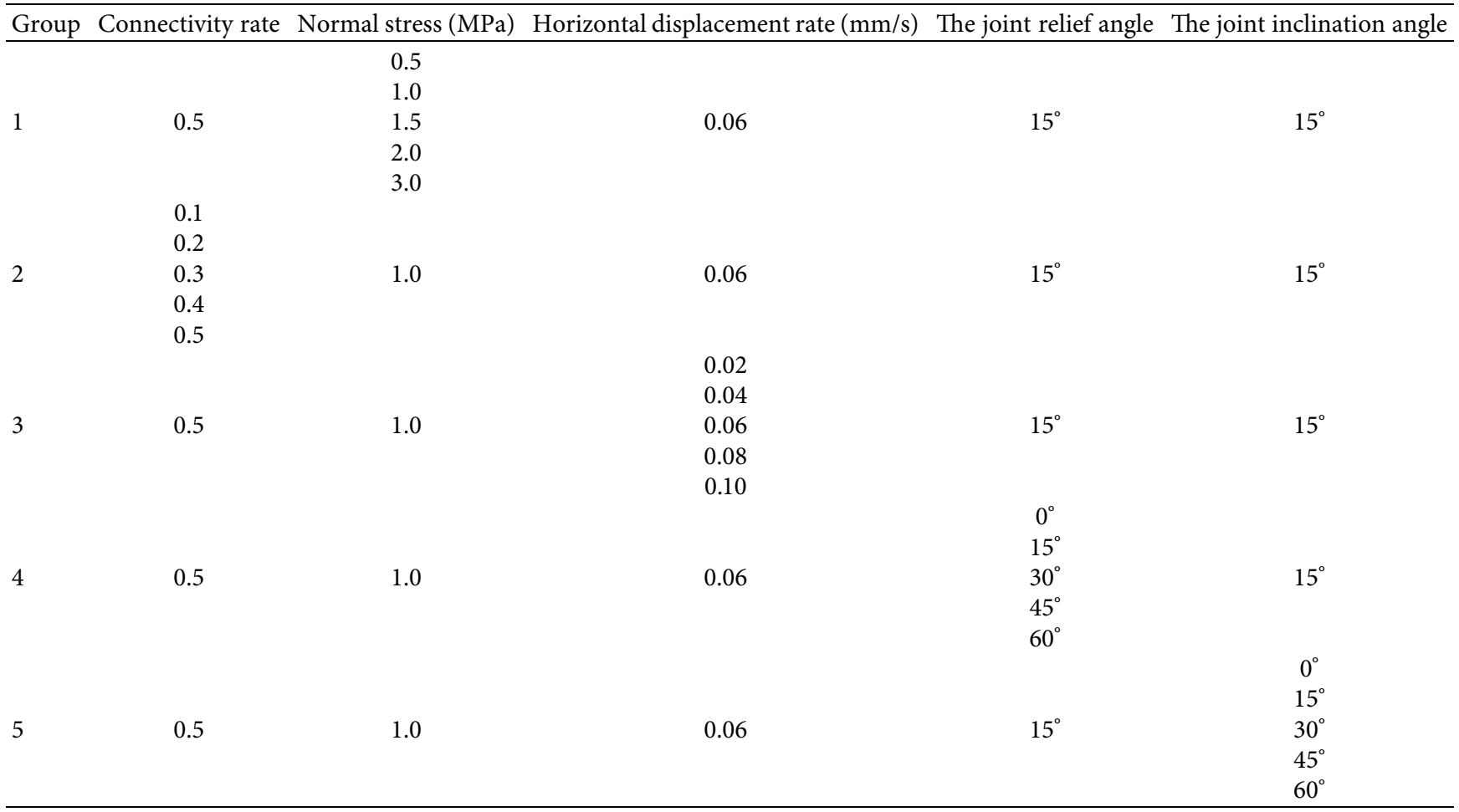

$15^{\circ}$, connectivity rate of 0.5 , and joint relief angles of $0^{\circ}, 15^{\circ}$, $30^{\circ}, 45^{\circ}$, and $60^{\circ}$, successively.

2.3.5. Group 5: Simulation Test of NNJRM with Different Joint Inclination Angles. When the shear rate is $0.06 \mathrm{~mm} / \mathrm{s}$ and the normal stress is $1.0 \mathrm{MPa}$, the numerical simulation tests were carried out for the NNJRM with a joint relief angle of $15^{\circ}$, connectivity rate of 0.5 , and joint inclination angles of $0^{\circ}$, $15^{\circ}, 30^{\circ}, 45^{\circ}$, and $60^{\circ}$, successively.

\section{Results and Discussion}

In this study, five groups of numerical models of rock mass with different conditions were simulated. The peak stress of the specimens, the total number of cracks in the rock mass (expressed by DFN), the number of cracks produced by tension (expressed by DFN-t), the number of cracks produced by shear (expressed by DFN-s), and the stress-strain relationship of five measuring points in the specimens were all studied to analyze the law of crack propagation and the mechanical properties of the rock mass.

3.1. Results of the First Experiment. The stress-strain curves and peak shear stress of NNJRM under different normal stresses of the first group of specimens are shown in Figure 8 and Table 3.

According to the data in Figure 8 and Table 3, it can be observed that when the normal stress increases from $0.5 \mathrm{MPa}$ to $3.0 \mathrm{MPa}$, the peak stress of NNJRM increases from $3.76 \mathrm{MPa}$ to $4.98 \mathrm{MPa}$, and the residual stress increases

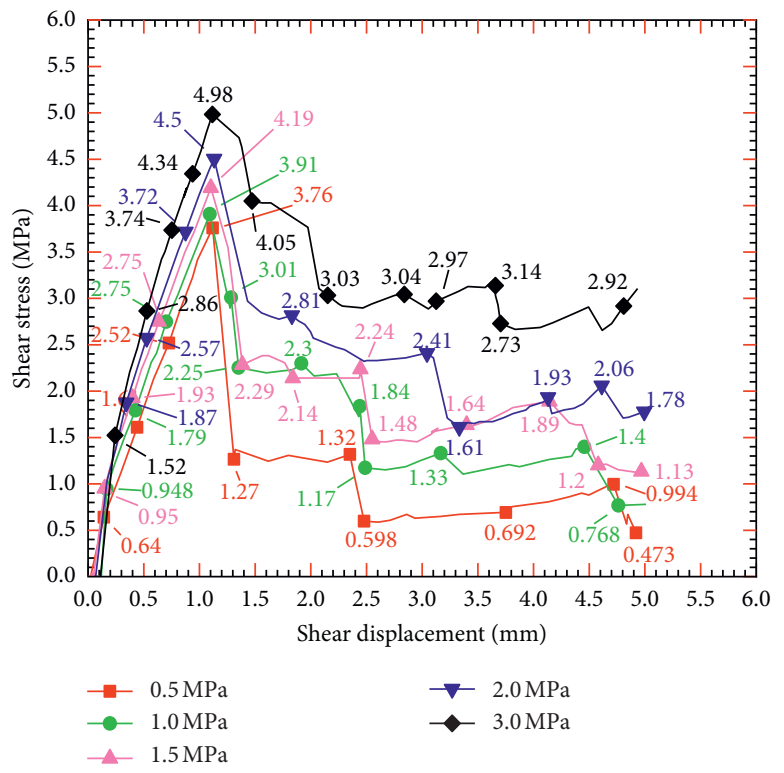

FIGURE 8: Stress-strain curves obtained from tests under different normal stresses.

TABLE 3: Peak shear stress of NNJRM under different normal stresses.

\begin{tabular}{lccccc}
\hline Normal stress $(\mathrm{MPa})$ & 0.5 & 1.0 & 1.5 & 2.0 & 3.0 \\
\hline Peak stress $(\mathrm{MPa})$ & 3.76 & 3.91 & 4.19 & 4.50 & 4.98 \\
\hline
\end{tabular}

from $0.47 \mathrm{MPa}$ to $3.15 \mathrm{MPa}$. It can be seen that with the increase in the normal stress in the test, both the shear strength and peak stress of NNJRM increase. 
The number of DFN, DFN-t, and DFN-s produced in the first group of specimens under different normal stresses are shown in Figure 9 and Table 4.

It can be seen from Figure 9 and the data in Table 4 that the number of cracks generated in the rock mass increased continuously in the course of the experiment until the end of the test. When the normal stress is gradually increased from $0.5 \mathrm{MPa}$ to $3.0 \mathrm{MPa}$, the total number of cracks in the rock mass increases from 293 to 515 . With the gradual increase in the normal stress from 0.5 MPa to 3.0 MPa, the number of DFN-t in the rock mass increases from 198 to 409, showing an obvious trend of increase. The number of DFN-s also changes with the change in normal stress, increasing from 95 to 106 , but the increase trend is not obvious. In addition, by comparing the number of DFN-t and DFN-s in Table 4, it is obvious that no matter how the normal stress changes, the number of cracks in each rock mass caused by tensile action is more than those caused by shear action. Therefore, during the direct shear test, the damage caused by the tensile action of the rock mass is more obvious. Thus, it can be said that the failure of rock mass in the test is mainly caused by tension.

In addition, the experiment under different normal stresses, the stress-strain curves, and the peak strength of each measuring circle are shown in Figure 10 and Table 5, respectively. After sorting out the data of the experiment under different normal stresses, the obtained curves of peak stress of each measured circle are shown in Figure 11.

It can be seen from the data in Figures 10 and 11 and Table 5 that with the change in the normal stress, the stress curve of each measured point in the rock mass changes significantly. On the one hand, for the same measurement point under different normal stresses: the peak stress of the rock mass will change with the increase in normal stress. The change in the peak stresses of measurement circles 1 and 5 is the most obvious. Here, the measurement circle 1 is taken as an example for analysis. When the normal stress is gradually increased from $0.5 \mathrm{MPa}$ to $3.0 \mathrm{MPa}$, the measured peak stresses are $6.27 \mathrm{MPa}, 6.32 \mathrm{MPa}, 10.25 \mathrm{MPa}, 10.2 \mathrm{MPa}$, and $7.43 \mathrm{MPa}$, respectively. The difference between the maximum peak stress and the minimum peak stress is $3.98 \mathrm{MPa}$. For the three other measurement circles, i.e. 3, 7, and 9, although their peak stress also changes with the increase in normal stress, the range of change is not obvious and is relatively stable. On the other hand, for the experiment with different measurement points under the same normal stress, by observing the stress curves of the five measurement points, it can be observed that no matter how much normal stress is applied during the direct shear test, the peak stress of the measurement point 5 is almost always the largest among the five measurement points. In addition, for this experiment, there is a big difference in the peak stress of measurement point 5 and that of the other measurement circles. When the normal stress is $3.0 \mathrm{Mpa}$, the peak stress at the measurement point 5 is $7.43 \mathrm{MPa}$, and although this is not the maximum value, the difference between this peak stress and the maximum peak stress of 8.44 MPa is still small. It can be seen that during the shear test, the stress of the rock mass is more concentrated at the middle part of the rock mass, that is, around the measuring circle 5, which bears the main shear stress.
3.2. Results of the Second Experiment. The stress-strain curves obtained by the direct shear test of the rock mass under different shear rates are shown in Figure 12. The peak stresses of the rock mass shown in Figure 12 are statistically analyzed, and the results are shown in Table 6.

According to the data in Figure 12 and Table 6, it can be found that the shear strength of the rock mass changes according to the change in the shear rate in the direct shear test. When the shear rate is $0.02 \mathrm{~mm} / \mathrm{s}$ and $0.06 \mathrm{~mm} / \mathrm{s}$, the peak shear stress of the rock mass is $3.85 \mathrm{Mpa}$ and $4.03 \mathrm{Mpa}$, respectively. Furthermore, when the shear rate is gradually increased to $0.10 \mathrm{~mm} / \mathrm{s}$, the peak shear stress of the rock mass increases to $4.3 \mathrm{MPa}$. Therefore, the peak stress of the rock mass increases with the increase in the shear rate, and the shear strength of the rock mass is also enhanced.

In addition, the number of DFN, DFN-t, and DFN-s produced in the second group of specimens for the experiment under different shear rates are shown in Figure 13 and Table 7.

According to the data in Figure 13 and Table 7, the shear rate has significant influence on the number of cracks in the rock mass during the direct shear test. First, the total number of cracks (DFN) is analyzed. It can be seen that when the shear rate is $0.02 \mathrm{~mm} / \mathrm{s}$ and $0.04 \mathrm{~mm} / \mathrm{s}$, the total number of cracks in the rock mass is 344 and 449 , respectively. However, when the shear rate continues to increase, the total number of cracks tends to decrease. For instance, when the shear rate is increased to $0.10 \mathrm{~mm} / \mathrm{s}$, the total number of cracks in the rock mass decreases to 371 . Therefore, it can be said that with the increase in the shear rate, the total number of cracks in the rock mass increases first and then decreases. Second, the quantity of DFN-t is analyzed, and it is found that the variation law of DFN-t is similar to that of DFN; the total number of cracks in the rock mass first increases and then decreases with the increase in the shear rate. For DFN-s, although the number of cracks also increases first and then decreases, the change is not obvious. Finally, by comparing the number of DFN-t and DFN-s, it is found that the number of DFN-t is much higher than that of DFN-s, the change of shear rate notwithstanding. Therefore, it can be concluded that, for the experiment under different shear rates, the number of cracks in the rock mass caused by tension is far higher than that caused by shear action. This means that the ultimate failure of a rock mass in the direct shear test is mainly caused by tension, rather than shear.

The stress-strain curves of each measurement circle under different shear rates are shown in Figure 14. The peak stress of each measurement circle is determined and presented in Table 8. The change curve of the peak stress of each measurement point under the condition of different shear rates is shown in Figure 15.

It can be seen from the data in Figures 14 and 15 and Table 8 that the shear rate has significant influence on rock mass stress.

(1) On the one hand, for the stress at the same measuring point under different shear rates: there is little change in peak stress of the four measurement circles 1 (except at $0.02 \mathrm{~mm} / \mathrm{s}$, the peak stress of the 


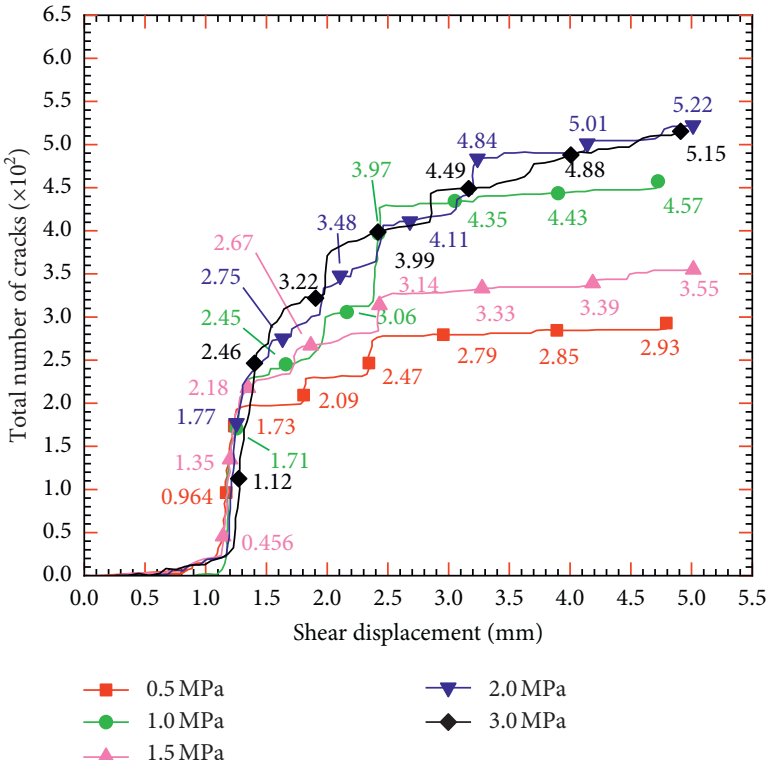

(a)

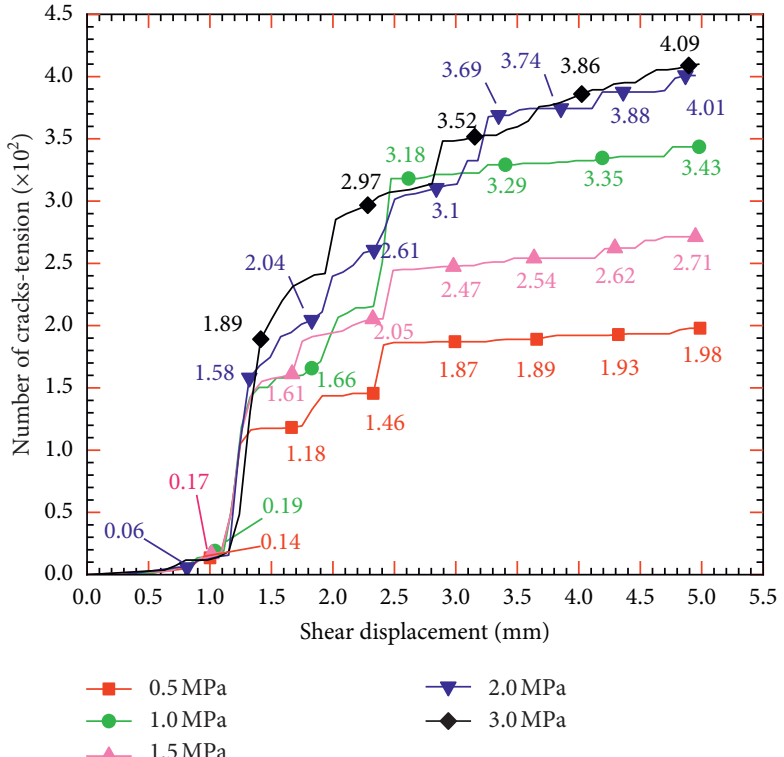

(b)

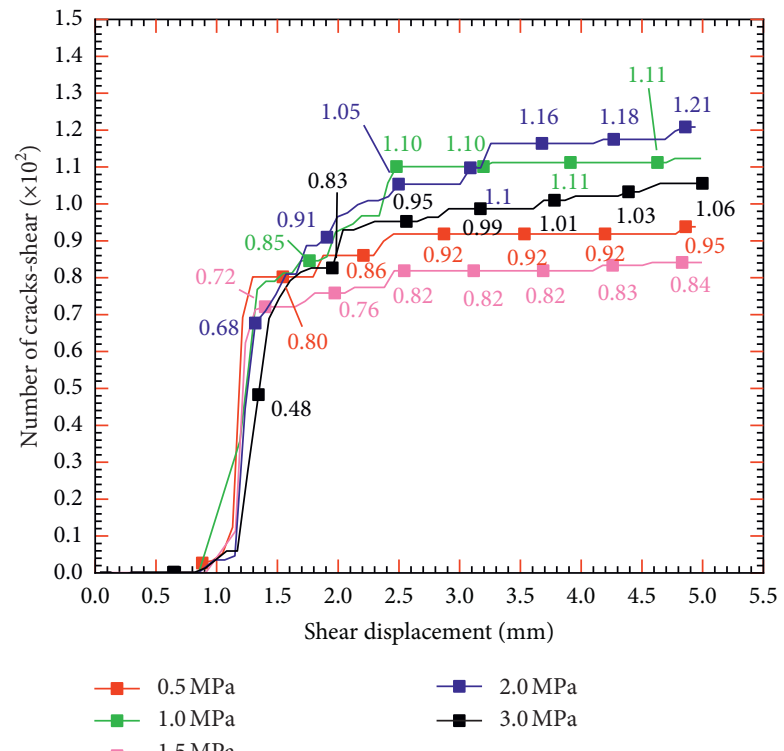

(c)

FIGURE 9: The number of cracks in the first group of specimens. (a) Total number of cracks. (b) The number of cracks caused by tension. (c) The number of cracks caused by shear action.

TABLE 4: The number of cracks generated under different normal stresses.

\begin{tabular}{lccccc}
\hline Normal stress (MPa) & 0.5 & 1.0 & 1.5 & 3.0 & \\
\hline DFN (strip) & 293 & 457 & 355 & 522 & \\
DFN-t (strip) & 198 & 343 & 271 & 401 & 409 \\
DFN-s (strip) & 95 & 114 & 84 & 121 & 106 \\
\hline
\end{tabular}

measurement circle 1 is discrete), 3, 7, and 9, when the shear rate is adjusted. However, for the measurement circle 5 , there is obvious change in the peak stress when the shear rate is adjusted. When the shear rate is increased from $0.02 \mathrm{~mm} / \mathrm{s}$ to $0.10 \mathrm{~mm} / \mathrm{s}$, the peak stress of measurement circle 5 decreases from 9.99 $\mathrm{MPa}$ to $4.91 \mathrm{MPa}$. This means that the peak stress of the measurement circle 5 gradually decreases with the increase in the shear rate. Therefore, with the increase in the shear rate, both the shear 

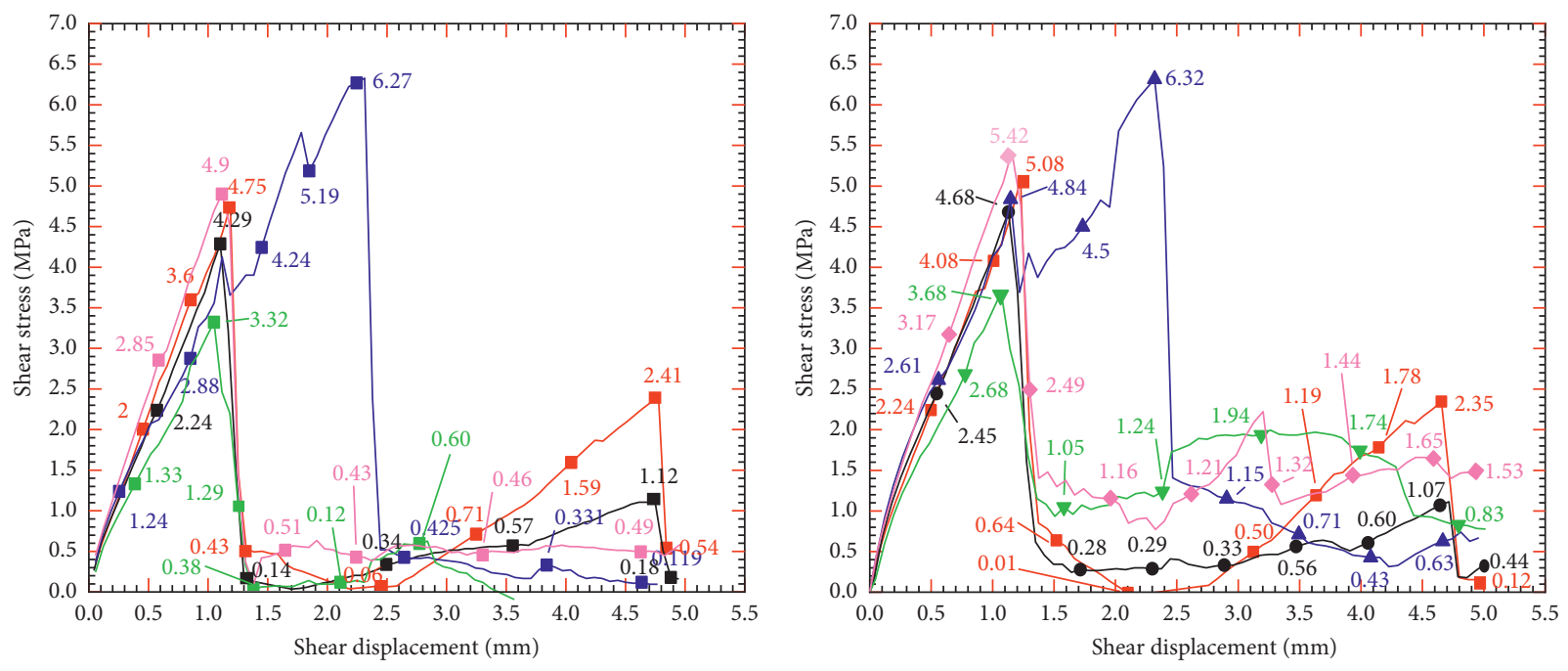

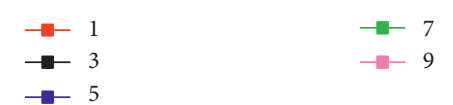

(a)

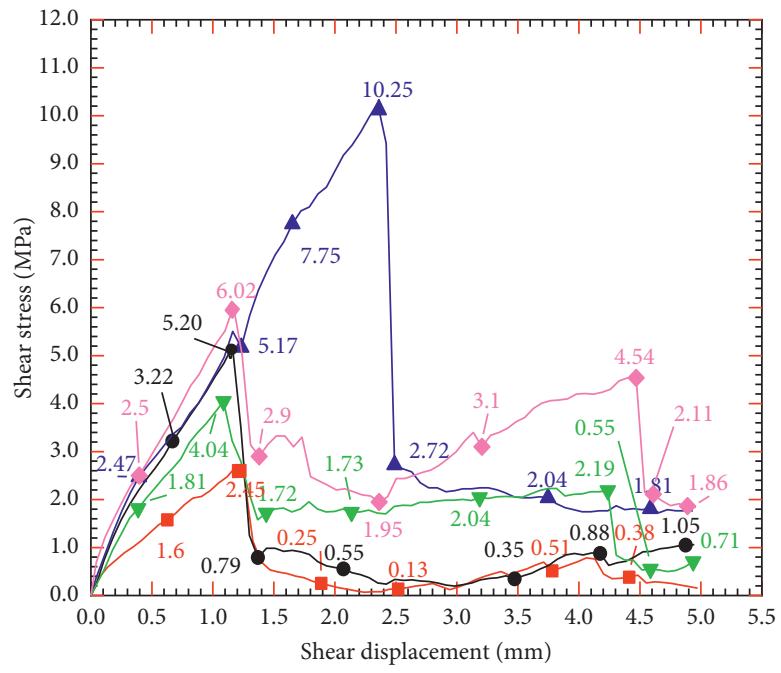

$-\quad 1$
$-\quad 3$
$-\quad 5$

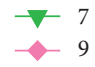

(c)

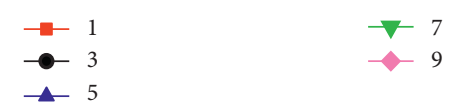

(b)

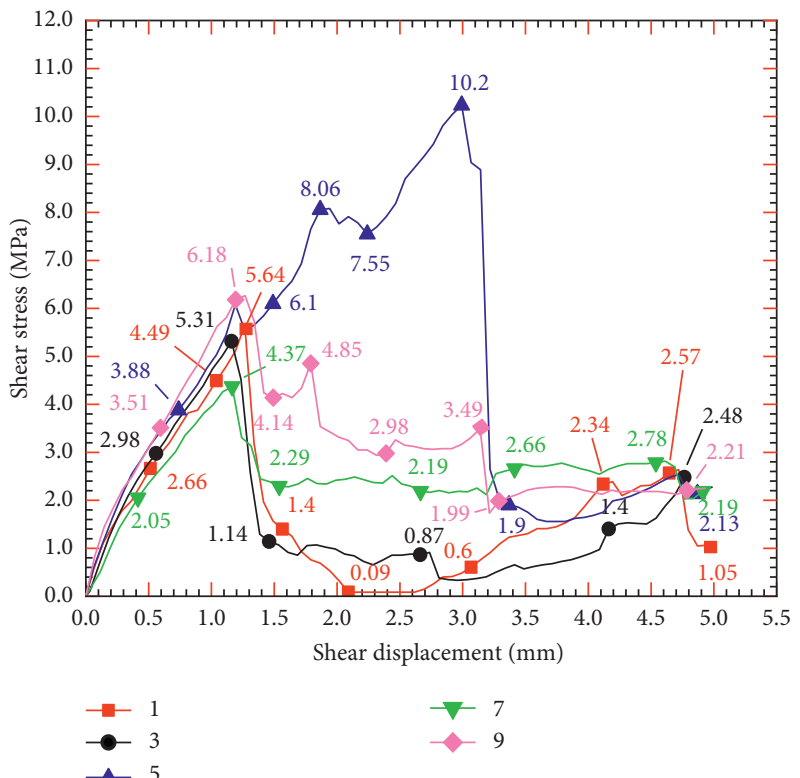

(d)

Figure 10: Continued. 


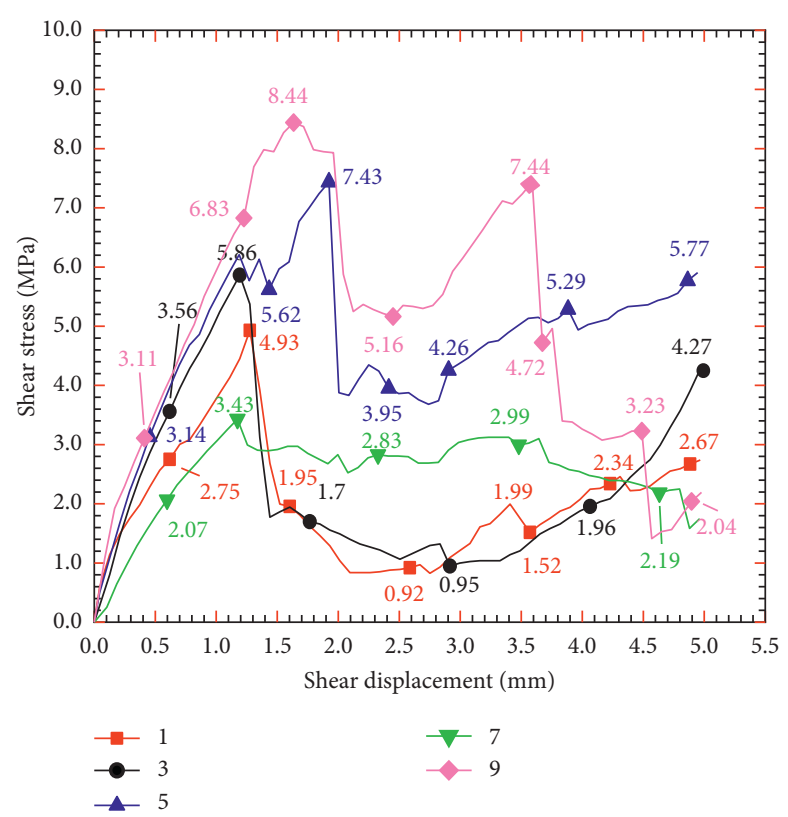

(e)

Figure 10: The stress-strain curves of the five measured circles in the first group of specimens when the normal stress is (a) $0.5 \mathrm{MPa}$, (b) $1.0 \mathrm{MPa}$, (c) $1.5 \mathrm{MPa}$, (d) $2.0 \mathrm{MPa}$, and (e) $3.0 \mathrm{MPa}$.

TABLE 5: The peak stress of each measurement circle in the first group of specimens ( $\mathrm{MPa})$.

\begin{tabular}{|c|c|c|c|c|c|}
\hline \multirow{2}{*}{ Number of measuring circles } & \multicolumn{5}{|c|}{ Normal stress $(\mathrm{MPa})$} \\
\hline & 0.5 & 1.0 & 1.5 & 2.0 & 3.0 \\
\hline 1 & 4.75 & 5.08 & 2.45 & 5.64 & 4.93 \\
\hline 3 & 4.29 & 4.68 & 5.20 & 5.31 & 5.86 \\
\hline 5 & 6.27 & 6.32 & 10.25 & 10.2 & 7.43 \\
\hline 7 & 3.32 & 3.68 & 4.04 & 4.37 & 3.43 \\
\hline 9 & 4.90 & 5.42 & 6.02 & 6.18 & 8.44 \\
\hline
\end{tabular}

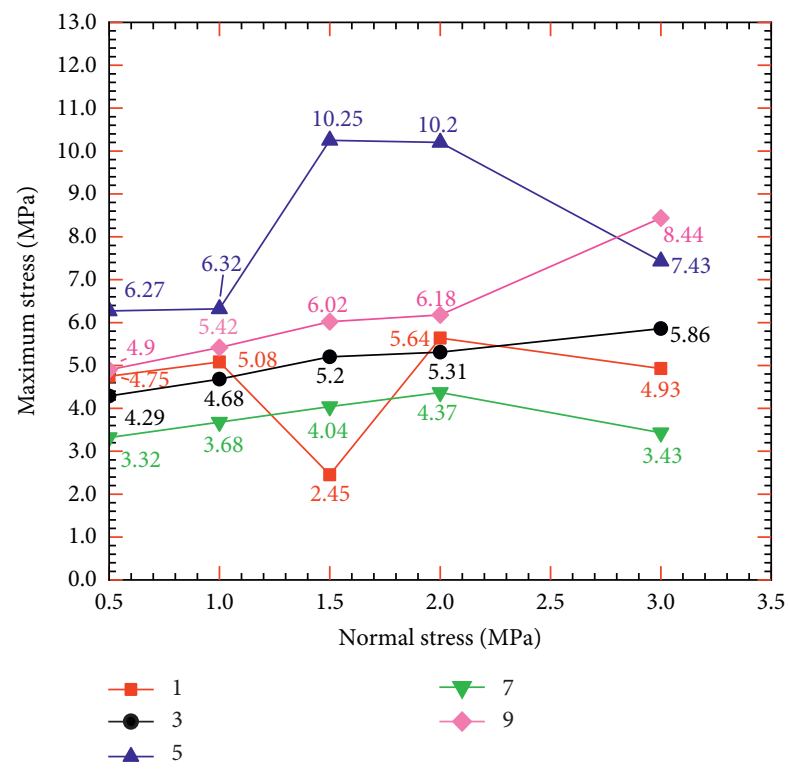

Figure 11: Curves of the peak stress of each measured circle in the first group of specimens. 


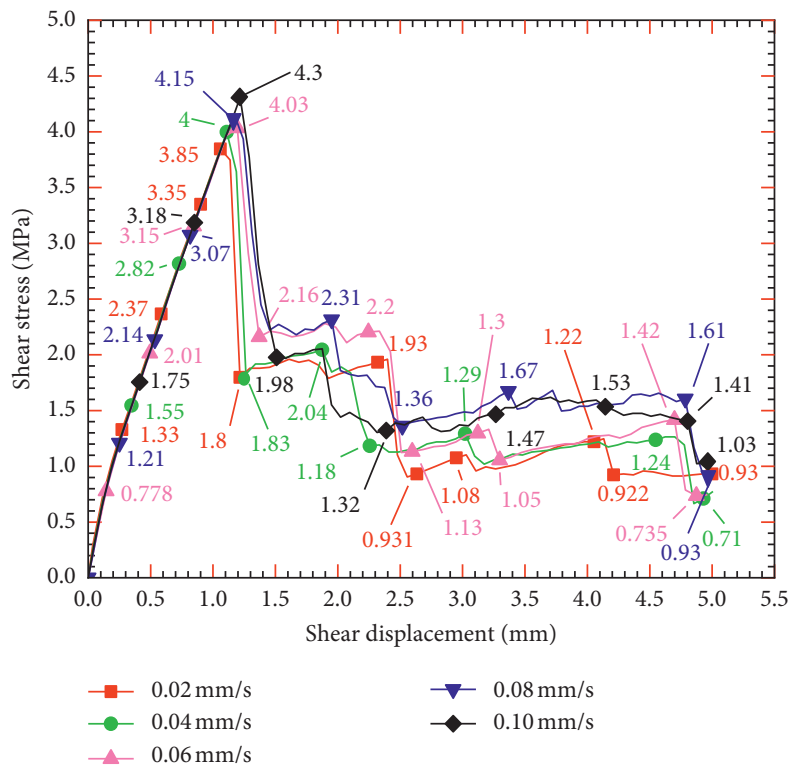

FIGURE 12: The stress-strain curves obtained from experiments under different shear rates.

TABLE 6: The peak shear stress of NNJRM under different shear rates.

\begin{tabular}{llllll}
\hline Shear rate $(\mathrm{mm} / \mathrm{s})$ & 0.02 & 0.04 & 0.06 & 0.08 & 0.10 \\
\hline Peak stress $(\mathrm{MPa})$ & 3.85 & 4.00 & 4.03 & 4.15 & \\
\hline
\end{tabular}

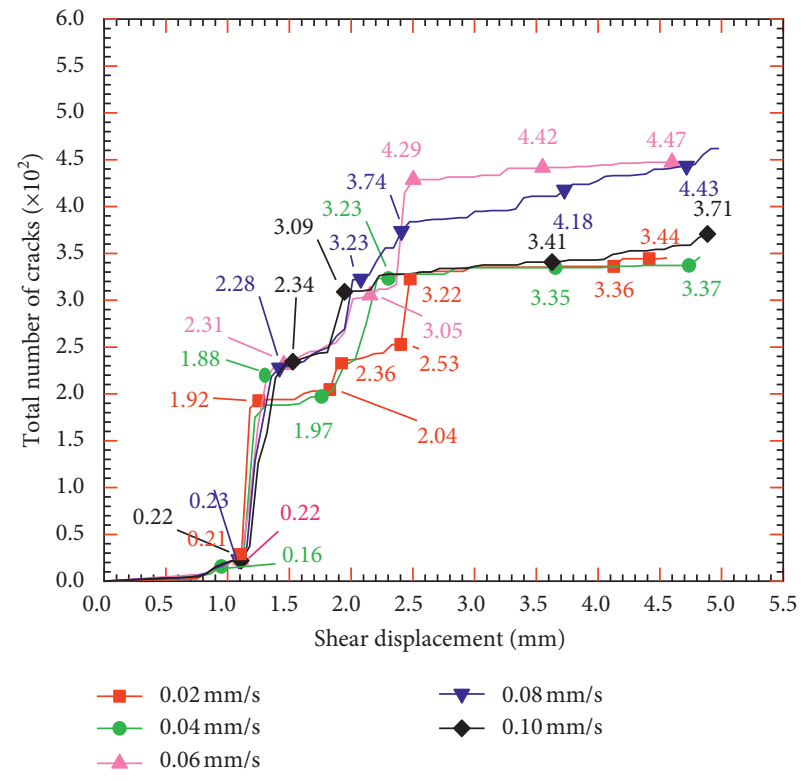

(a)

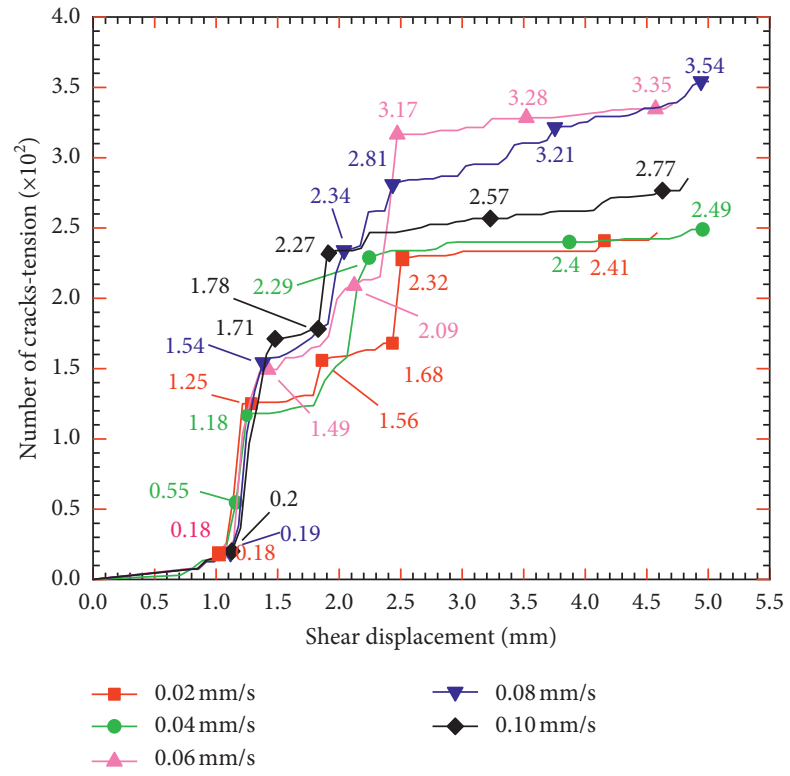

(b)

FIGURE 13: Continued. 


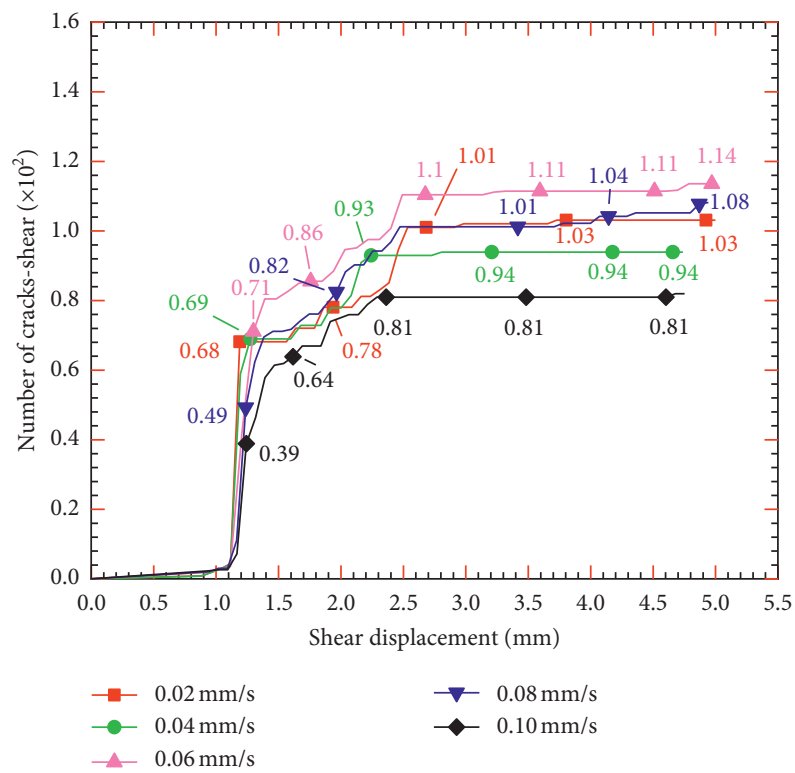

(c)

FIGURE 13: The number of cracks in the second group of specimens. (a) Total number of cracks. (b) The number of cracks caused by tension. (c) The number of cracks caused by shear action.

TABLE 7: The number of cracks generated under different shear rates.

\begin{tabular}{lccccc}
\hline Shear rate $(\mathrm{mm} / \mathrm{s})$ & 0.02 & 0.04 & 0.06 & 0.08 & \\
\hline DFN (strip) & 344 & 343 & 449 & 462 & 371 \\
DFN-t (strip) & 241 & 249 & 335 & 354 & 289 \\
DFN-s (strip) & 103 & 94 & 114 & 108 & 82 \\
\hline
\end{tabular}

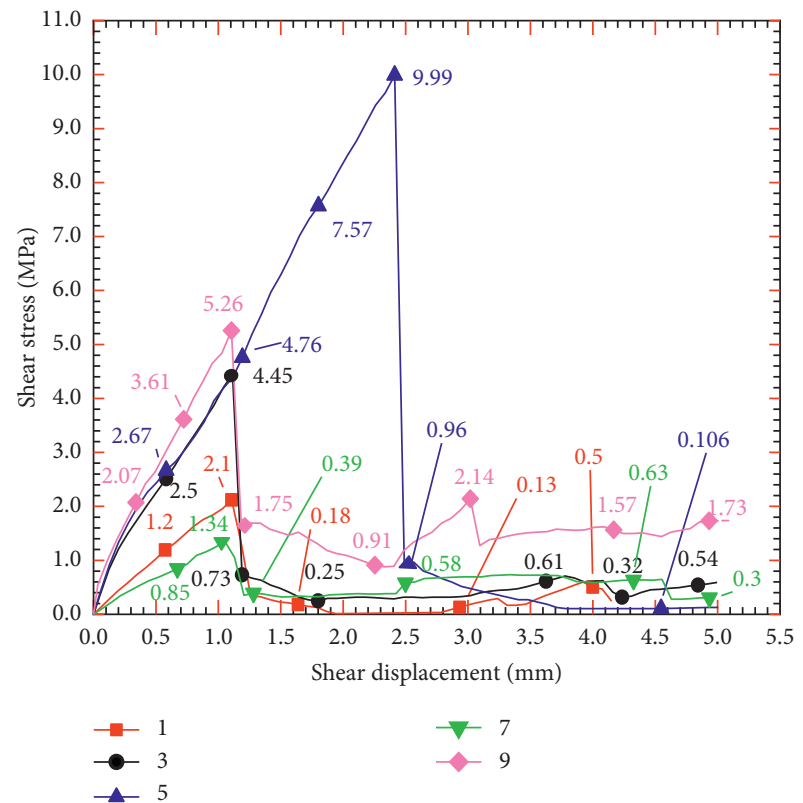

(a)

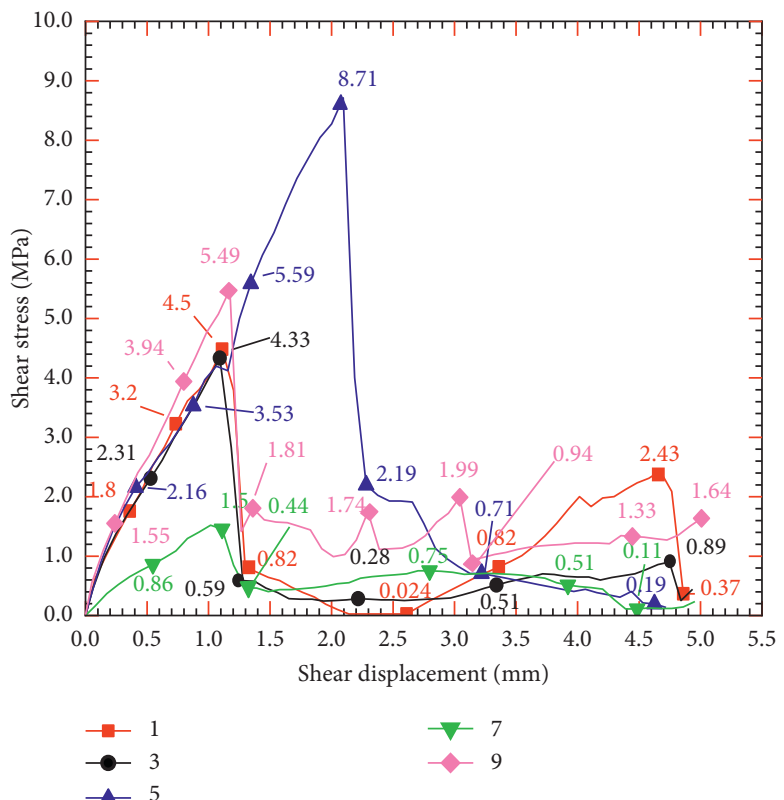

(b)

Figure 14: Continued. 


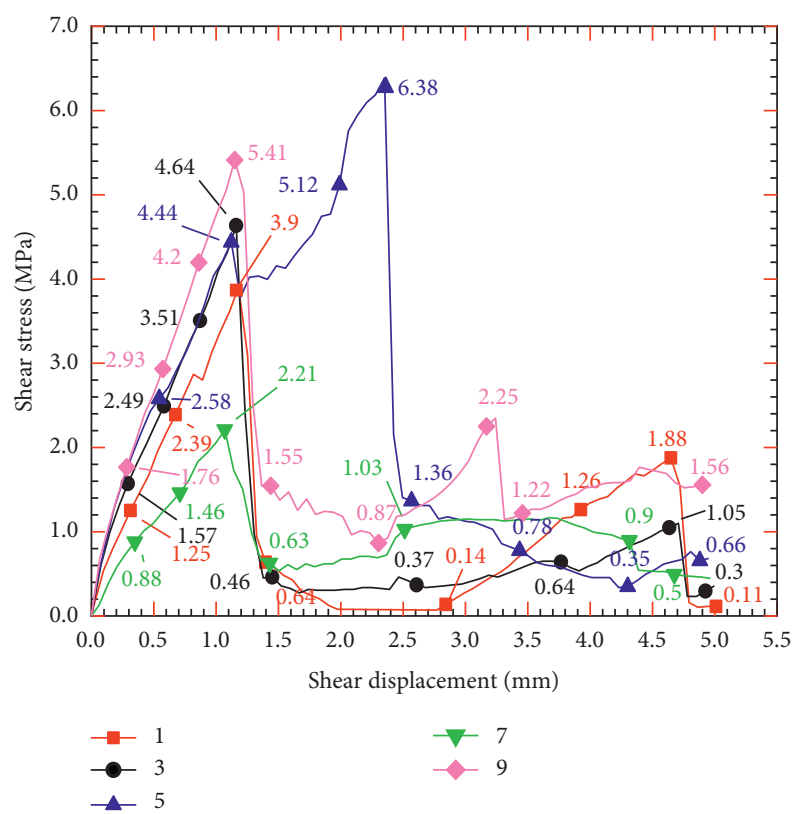

(c)
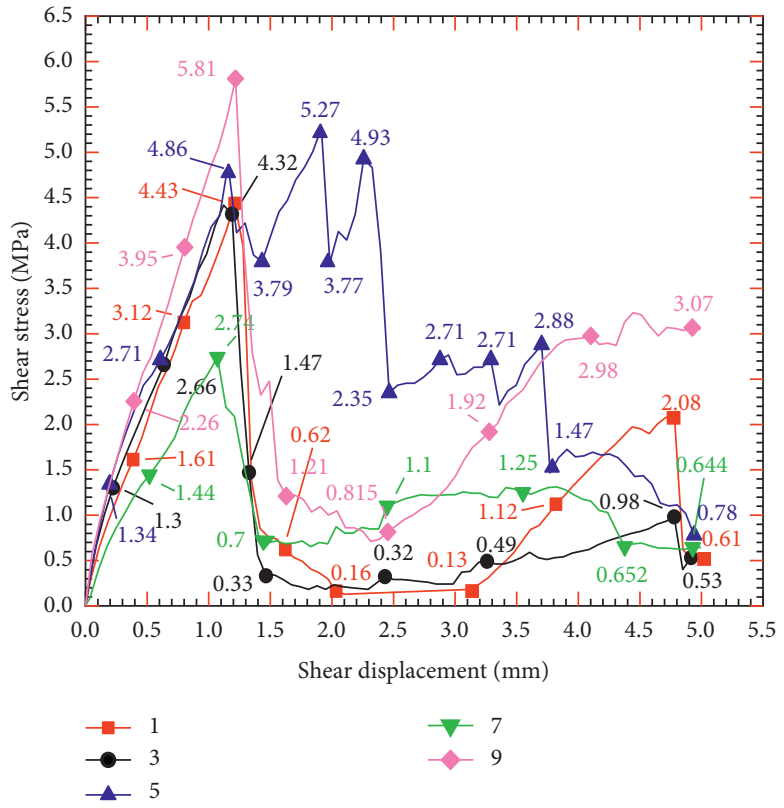

$-7$

(d)

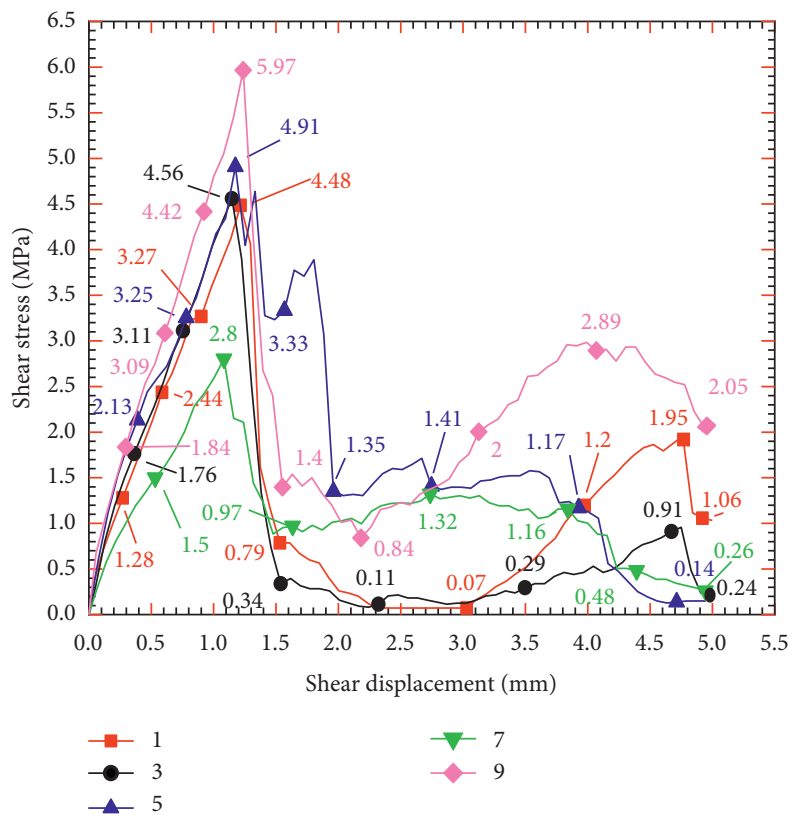

(e)

Figure 14: Stress-strain curves of each measurement circle in the second group of specimens when the shear rate is (a) $0.02 \mathrm{~mm} / \mathrm{s}$, (b) $0.04 \mathrm{~mm} / \mathrm{s}$, (c) $0.06 \mathrm{~mm} / \mathrm{s}$, (d) $0.08 \mathrm{~mm} / \mathrm{s}$, and (e) $0.10 \mathrm{~mm} / \mathrm{s}$.

TABLE 8: The peak stress of each measurement circle in the second group of specimens.

\begin{tabular}{|c|c|c|c|c|c|}
\hline \multirow{2}{*}{ Number of measuring circles } & \multicolumn{5}{|c|}{ Shear rate $(\mathrm{mm} / \mathrm{s})$} \\
\hline & 0.02 & 0.04 & 0.06 & 0.08 & 0.10 \\
\hline 1 & 2.10 & 4.50 & 3.9 & 4.43 & 4.48 \\
\hline 3 & 4.45 & 4.33 & 4.64 & 4.32 & 4.56 \\
\hline 5 & 9.99 & 8.71 & 6.38 & 5.27 & 4.91 \\
\hline 7 & 1.34 & 1.51 & 2.21 & 2.74 & 2.80 \\
\hline 9 & 5.26 & 5.49 & 5.41 & 5.81 & 5.97 \\
\hline
\end{tabular}




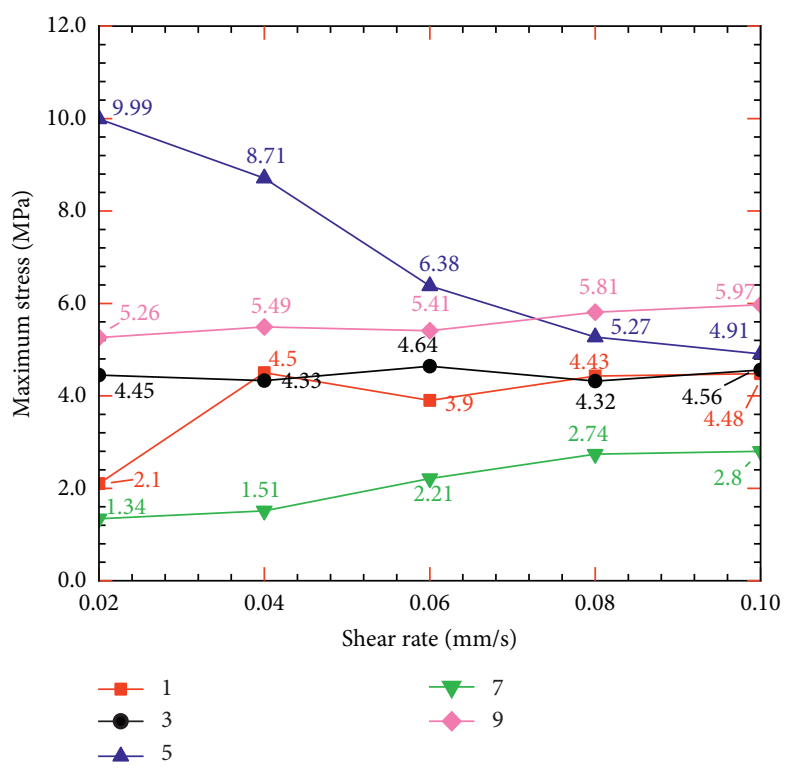

FIGURE 15: Curves of peak stress of each measured circle in the second group of specimens.

capacity and shear stress at the center point of the rock mass decrease. In addition, as can be seen from the data in Figure 12 and Table 6, the peak stress and the shear strength of the whole rock mass increase with the increase in the shear rate during the test. In summary, as the shear rate increases, the shear stress borne by the center of the rock mass decreases, and the force borne by the interior of the rock mass gradually balances.

(2) On the other hand, for the stress of different measurement circles under the same shear rate condition: the peak stresses of the measurement circle 5 at the shear rates of $0.02 \mathrm{~mm} / \mathrm{s}, 0.04 \mathrm{~mm} / \mathrm{s}$, and $0.06 \mathrm{~mm} / \mathrm{s}$ are $9.99 \mathrm{MPa}, 8.71 \mathrm{MPa}$, and $6.38 \mathrm{MPa}$, respectively, and these are the maximum values of the peak stress of the five measurement circles. In addition, when the shear rates are $0.08 \mathrm{~mm} / \mathrm{s}$ and $0.10 \mathrm{~mm} / \mathrm{s}$, the peak stresses at the measurement circle 5 are $5.27 \mathrm{MPa}$ and $4.91 \mathrm{MPa}$, respectively. Although these values differ slightly with the maximum value, they are still relatively large compared with those of other measurement circles. Therefore, in general, under different shear rates, the central position of a rock mass specimen is subjected to greater shear action and the stress variation is more obvious.

3.3. Results of the Third Experiment. The stress-strain curve obtained after the direct shear test of the rock mass with different joint connectivity rates is shown in Figure 16. The peak stress of the rock mass in Figure 16 is sorted out, and the results are presented in Table 9.

According to the data in Figure 16 and Table 9, it can be found that the test results of NNJRM with different joint connectivity rates have obvious consistency. When the connectivity of joints within the rock mass is 0.1 , the peak shear stress of the rock mass is $5.90 \mathrm{MPa}$, and the residual stress is $1.34 \mathrm{MPa}$. When the joint connectivity rate increases gradually, the peak stress and residual stress of the rock mass tend to decrease. When the joint connectivity rate increases to 0.5 , the peak shear stress and residual stress decrease to 4.03 $\mathrm{MPa}$ and $0.75 \mathrm{MPa}$, respectively. Therefore, the smaller the joint connectivity, the greater the peak stress and residual stress of the rock mass. Furthermore, the stronger the shear capacity of a rock mass, the stronger the ability to resist external forces.

In addition, the number of DFN, DFN-t, and DFN-s produced in the third group of specimens with different joint connectivity rates are shown in Figure 17 and Table 10.

By summarizing and sorting out the data in Figure 17 and Table 10, it can be found that no matter the value of the joint connectivity rate, the number of cracks generated in the rock mass gradually increases with the progress of the test process. However, different joint connectivity rates generate different increment rates of cracks. When the connectivity of joints was 0.1 , the number of DFN, DFN-s, and DFN-t increased to 829,189 , and 640 , respectively. When the joint connectivity rate gradually increased to 0.5 , the final total number of cracks in the experimental rock mass decreased to 457, among which 114 are DFN-s and 343 are DFN-t.

According to these data, the number of these two kinds of cracks, DFN-s, and DFN-t, which are caused by different forms of forces, decreases with the increase in joint connectivity, leading to a decrease in the total amount of cracks in the rock mass. Therefore, it can be concluded that the smaller the connectivity of joints within the rock mass, the better the integrity of the rock mass and the stronger the shear resistance capability of the rock mass. This is consistent with practical experiences in engineering practice.

The stress-strain curves of each measuring circle in the specimens with different joint connectivity rates are shown in Figure 18. The peak stress of each measuring circle is sorted out as shown in Table 11, and the change curve of 


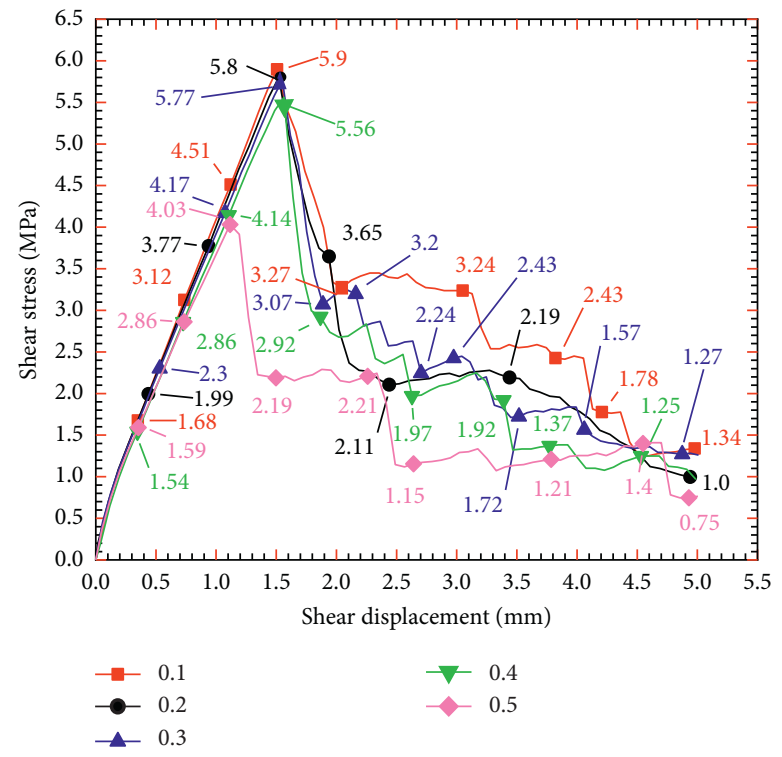

FiguRE 16: The stress-strain curve of the rock mass with different joint connectivity rates.

TABLE 9: The peak shear stress of NNJRM with different joint connectivity rates.

\begin{tabular}{lccccc}
\hline Connectivity rate & 0.1 & 0.2 & 0.3 & 0.4 & 0.5 \\
\hline Peak shear stress $(\mathrm{MPa})$ & 5.90 & 5.80 & 5.77 & 5.56 & 4.03 \\
\hline
\end{tabular}

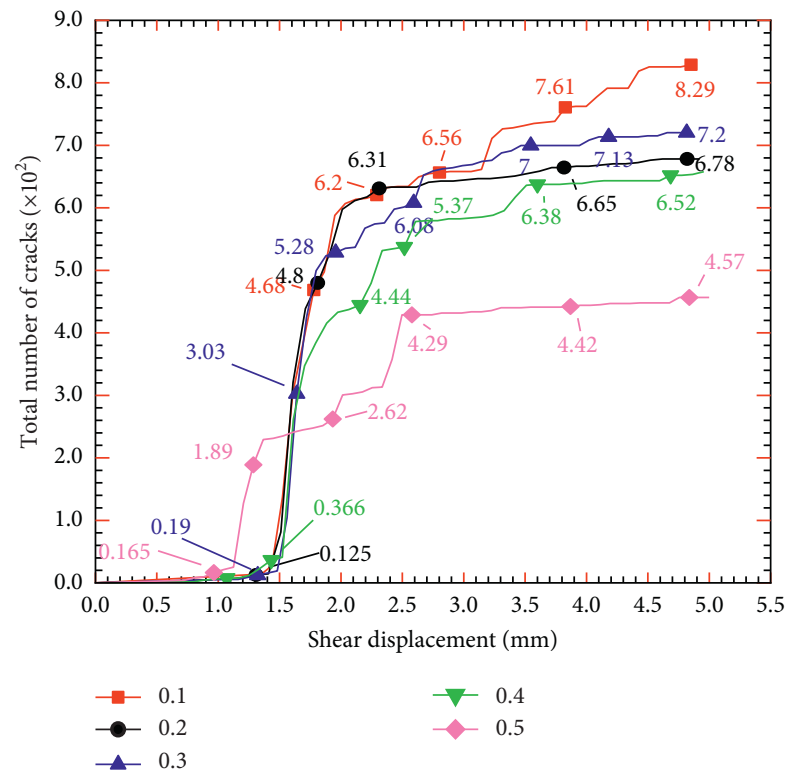

(a)

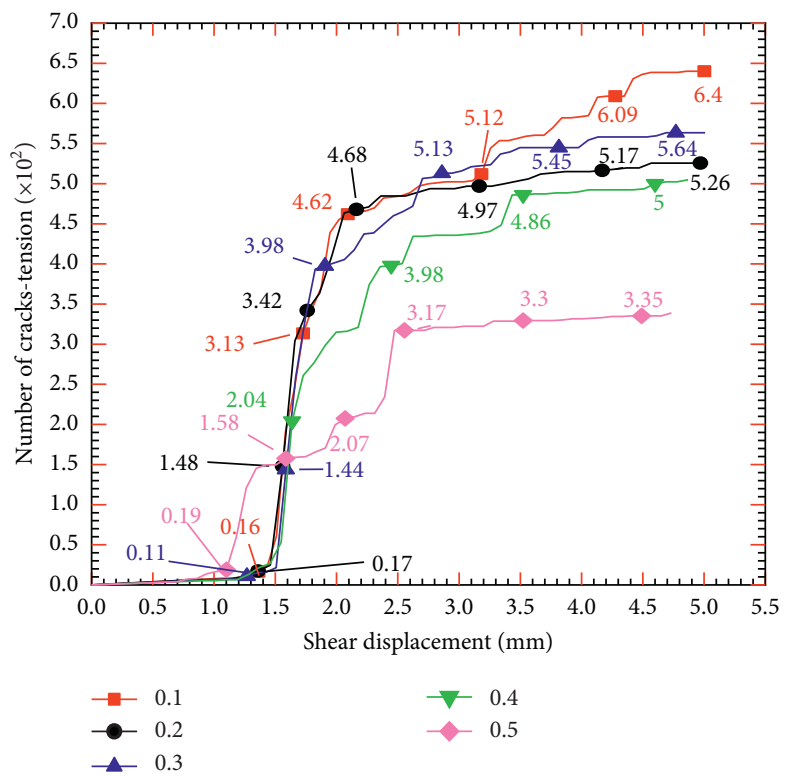

(b)

Figure 17: Continued. 


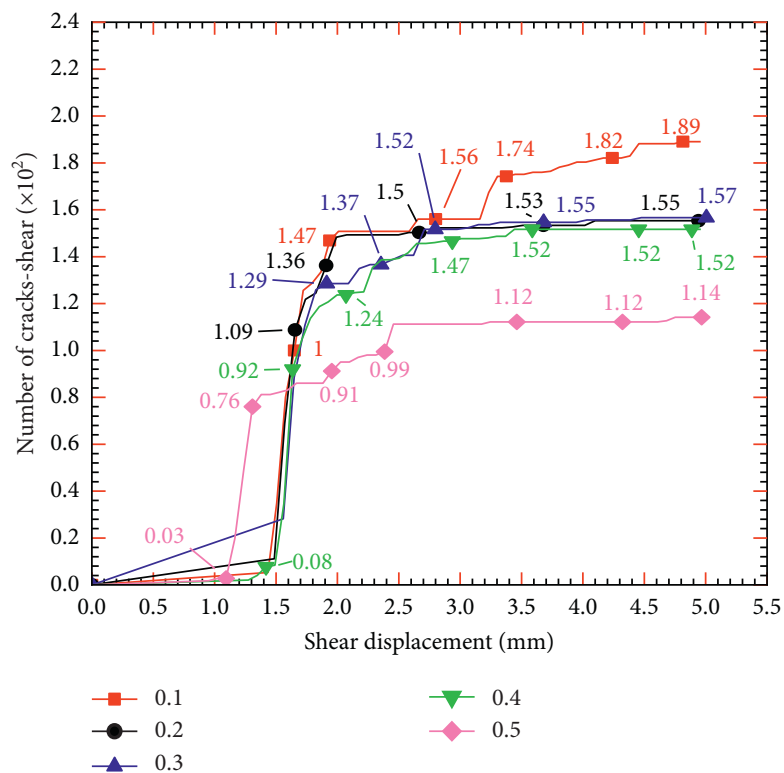

(c)

FIGURE 17: The number of cracks in the third group of specimens. (a) Total number of cracks. (b) The number of cracks caused by tension. (c) The number of cracks caused by shear action.

TABLE 10: The number of cracks generated at different connectivity rates.

\begin{tabular}{|c|c|c|c|c|c|}
\hline Connectivity rate & 0.1 & 0.2 & 0.3 & 0.4 & 0.5 \\
\hline DFN (strip) & 829 & 681 & 720 & 654 & 457 \\
\hline DFN-t (strip) & 640 & 526 & 563 & 502 & 343 \\
\hline DFN-s (strip) & 189 & 155 & 157 & 152 & 114 \\
\hline
\end{tabular}

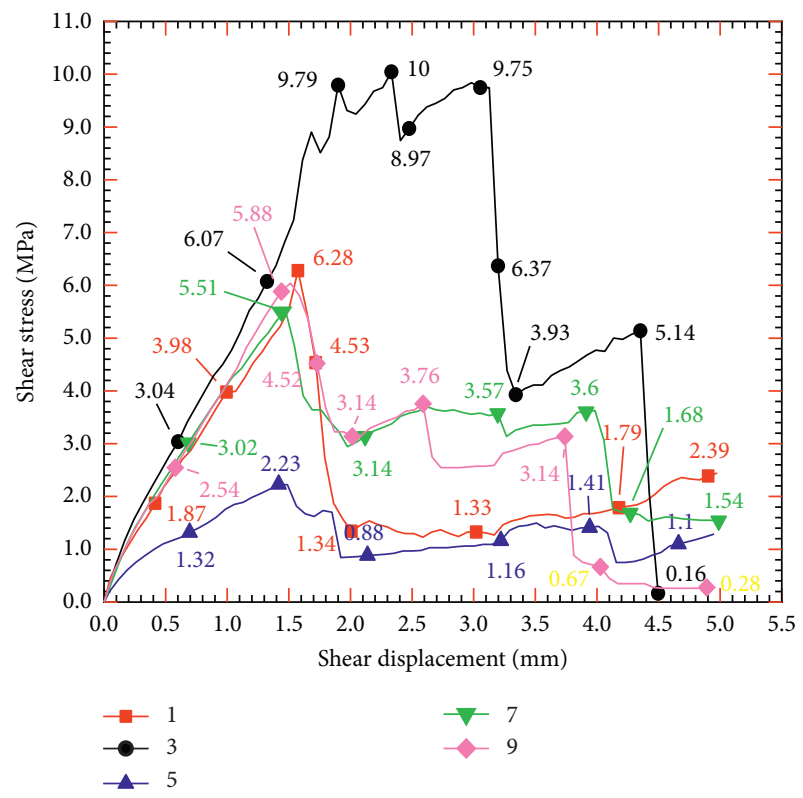

(a)

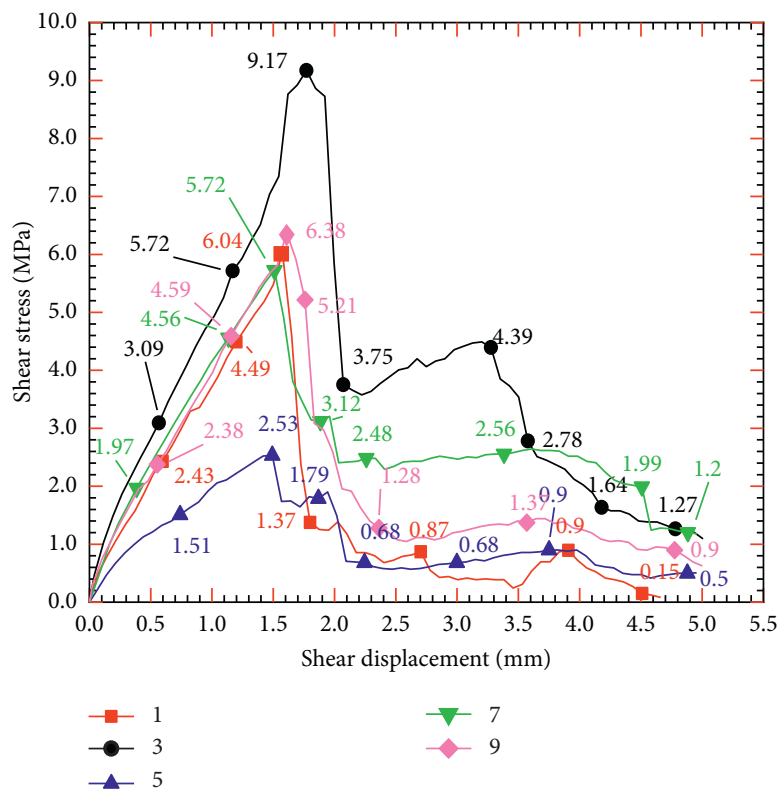

(b)

Figure 18: Continued. 

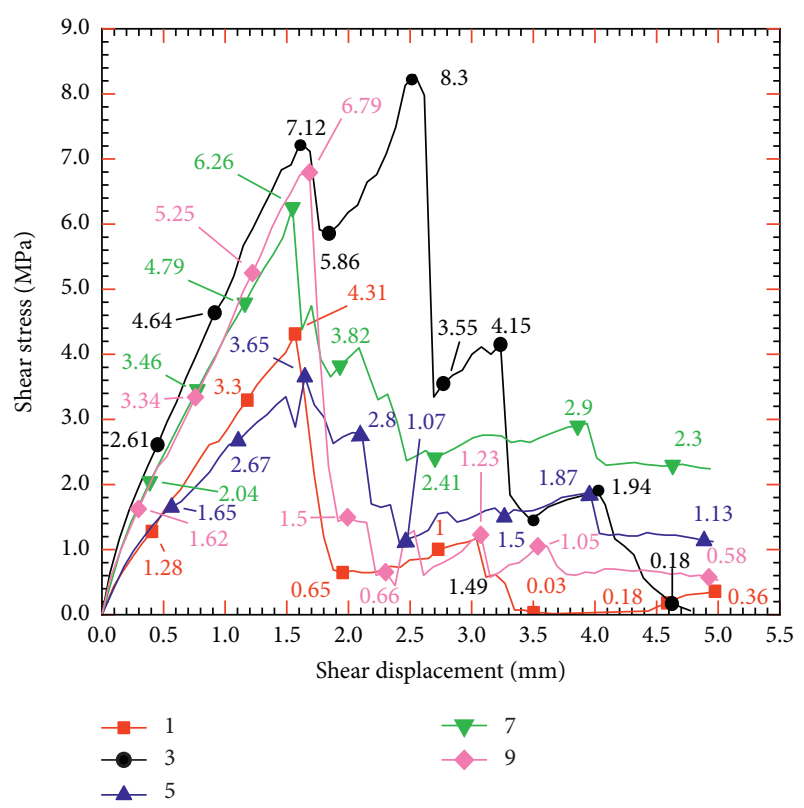

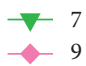

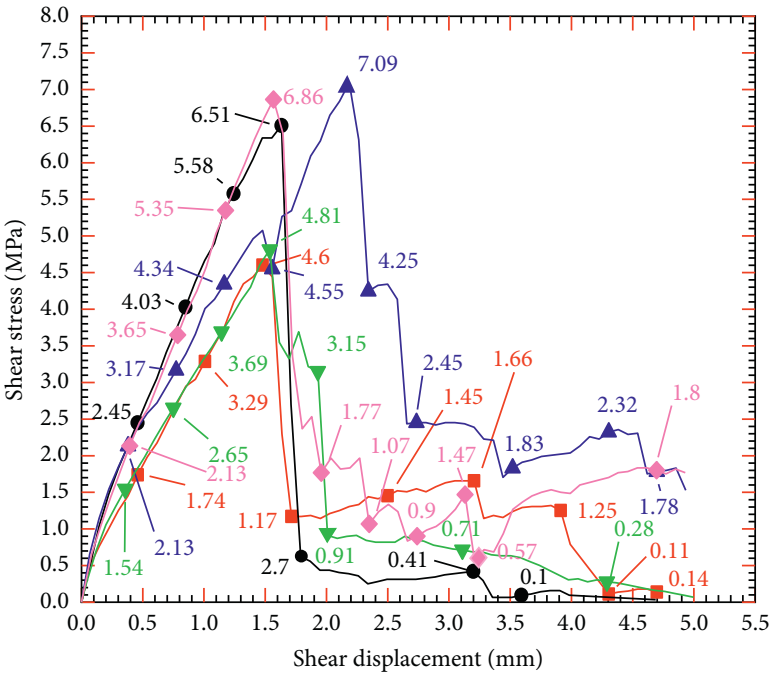

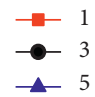

$-7$

(d)

(c)
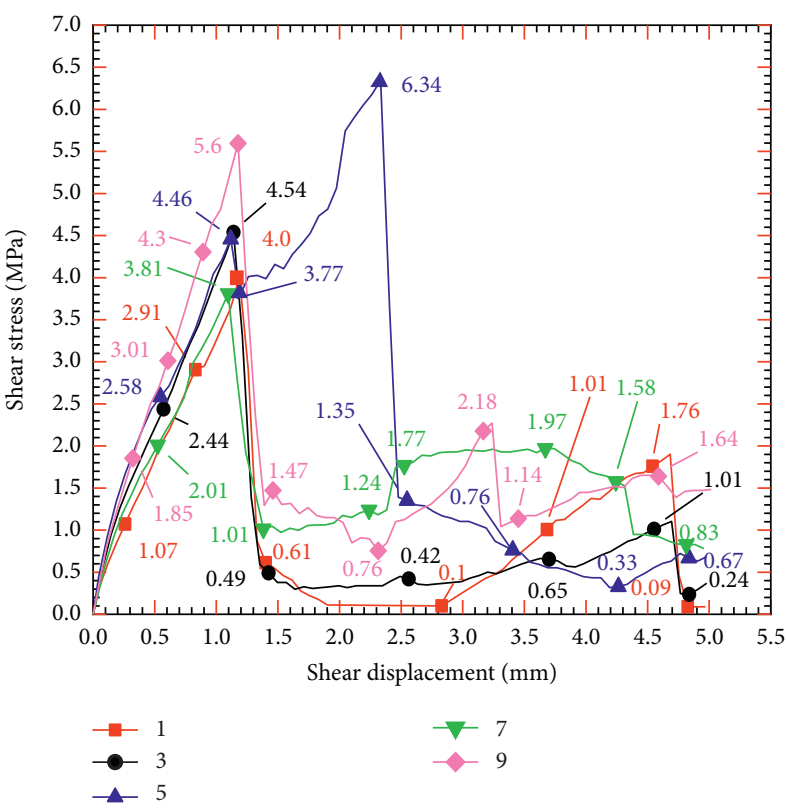

(e)

FIGURE 18: Stress-strain curves of each measurement circle in the third group of specimens when the connectivity rate is (a) 0.1 , (b) 0.2 , (c) 0.3 , (d) 0.4 , and (e) 0.5 .

TABLE 11: The peak stress of each measurement circle in the third group of specimens.

\begin{tabular}{|c|c|c|c|c|c|}
\hline \multirow{2}{*}{ Number of measuring circles } & \multicolumn{5}{|c|}{ Connectivity rate } \\
\hline & 0.1 & 0.2 & 0.3 & 0.4 & 0.5 \\
\hline 1 & 6.28 & 6.05 & 4.31 & 4.6 & 4.00 \\
\hline 3 & 10.0 & 9.17 & 8.30 & 6.51 & 4.54 \\
\hline 5 & 2.23 & 2.53 & 3.65 & 7.09 & 6.34 \\
\hline 7 & 5.51 & 5.72 & 6.26 & 4.81 & 3.81 \\
\hline 9 & 5.91 & 6.38 & 6.79 & 6.86 & 5.60 \\
\hline
\end{tabular}


peak stress of each measurement point under the condition of different joint connectivity rates is obtained, as shown in Figure 19.

Based on the data shown in Figures 18 and 19 and Table 11, we find that, unlike direct shear tests conducted under the above controlled conditions, the maximum peak shear stress is not always at the measurement circle 5 located at the center of the specimen when the test is carried out at different joint connectivity rates. When the connectivity of the joints in the rock mass ranges from 0.1 to 0.3 , the peak shear stress of the measurement circle 3 in the rock mass is the largest among the five measuring points. The peak stresses of measurement circles 1,7 , and 9 near both sides of the rock mass are large, while that of measuring circle 5 in the middle of the specimen is the smallest. Therefore, when the connection rate of joints is 0.1 to 0.3 , the rock mass close to both sides of the rock mass bears more stress. However, when the connectivity of joints increases to 0.4 or 0.5 , the measurement circle 5 experiences the highest peak stress among the five measuring points, and the peak stress of the five measurement circles is more uniform.

3.4. Results of the Fourth Experiment. The curves of stressstrain and peak shear stress of NNJRM with different joint relief angles of the fourth group specimens are shown in Figure 20 and Table 12.

According to the data in Figure 20 and Table 12, it can be found that the relief angle of joints has an influence on the stress-strain curve of NNJRM. If the joint relief angle changes, the peak shear stress and residual stress of the rock mass show obvious changes. However, there is no obvious regularity to this change.

The number of DFN, DFN-t, and DFN-s produced in the fourth group of specimens with different relief angles are shown in Figure 21 and Table 13.

By comparing the number of DFN, DFN-s, and DFN-t in the rock mass with five kinds of joint relief angles, it can be found that the change of joint relief angle has obvious influence on the direct shear test of a jointed rock mass. The difference between the maximum value (634) and the minimum value (342) of the total number of cracks produced by the direct shear test on the rock mass with different joint relief angles is 292. Similarly, the difference between the maximum value (504) and the minimum value (263) of the number of DFN-t is 241. Furthermore, under the same joint relief angle, the number of DFN-s generated in the specimen is significantly less than that of DFN-t. Therefore, the following conclusions can be drawn: in the direct shear tests of a rock mass with different joint relief angles, the main reason for its failure is the action of tension rather than the shear action.

The stress-strain curves of each measurement circle in the fourth group of specimens with different joint relief angles are shown in Figure 22. The peak stress of each measurement circle of the specimens under each joint relief angle is sorted out as shown in Table 14, and the change curve of the peak stress of each measured point with different joint relief angles is obtained, as shown in Figure 23.
According to the data in Figures 22 and 23 and Table 14, when conducting direct shear test on the rock mass with joints with different undulating angles, the measurement circle 5 of the rock mass experiences the largest peak stress among the five measurement circles. It is proved that the central part of the rock mass with discontinuous joints bears more forces during the direct shear test. In addition, according to the curve in Figure 23, when the joint relief angle is $0^{\circ}$ or $60^{\circ}$, the peak stress of each measurement circle in the rock mass varies greatly and the stress distribution is not uniform.

3.5. Results of the Fifth Experiment. The curve of stress-strain and peak shear stress of NNJRM with different inclination angles of the fifth group of specimens are shown in Figure 24 and Table 15.

We can see from the data in Figure 24 and Table 15 that when the joint inclination angle is $0^{\circ}$ and $15^{\circ}$, the peak stress of the rock mass is $3.95 \mathrm{MPa}$ and $4.01 \mathrm{MPa}$, respectively. If the angle is increased to $60^{\circ}$, the peak shear stress increases to $6.00 \mathrm{MPa}$. It can be seen that the peak stress of the rock mass increases with the increase in the joint inclination angle. Therefore, when the inclined angle of the joints is increased, the shear strength of the rock mass with different plane joints is enhanced.

The number of cracks generated by the fifth group of specimens during the experiment is shown in Figure 25 and Table 16.

From the chart and table above, it can be found that the dip angle of the joints has a significant effect on the crack propagation of the incoherent jointed rock mass. When the inclination angle of joints is changed, the number of cracks generated in the rock mass shows a very obvious change. However, there is no specific rule for the change in the number of cracks. Although the variation law of DFN, DFN$t$, and DFN-s is not obvious, the number of DFN-t is always more than that of DFN-s. It is proved that the final failure of the NNJRM with different inclination angles in the direct shear test is also caused by tension.

The stress-strain curves of each measurement circle in the specimens with different joint inclination angles are shown in Figure 26. The peak stress of each measuring circle is sorted out as shown in Table 17, and the change curve of peak stress of each measured point under the condition of different joint inclination angles is obtained, as shown in Figure 27.

Based on the data obtained through the above simulation experiment, it can be seen that the joint inclination angle has significant influence on the strength characteristics of the rock mass. Although it is not possible to establish a specific law that reflects the influence of the joint inclination angle on the peak stress at each position in the rock mass, it is certain that the peak stress of the five measurement circles in the rock mass varies with the change in the joint inclination angle. Moreover, when the joint inclination angle is $15^{\circ}$, the peak stresses of the five measurement circles in the rock mass are not significantly different, and the stress distribution in the model specimen is more uniform. 


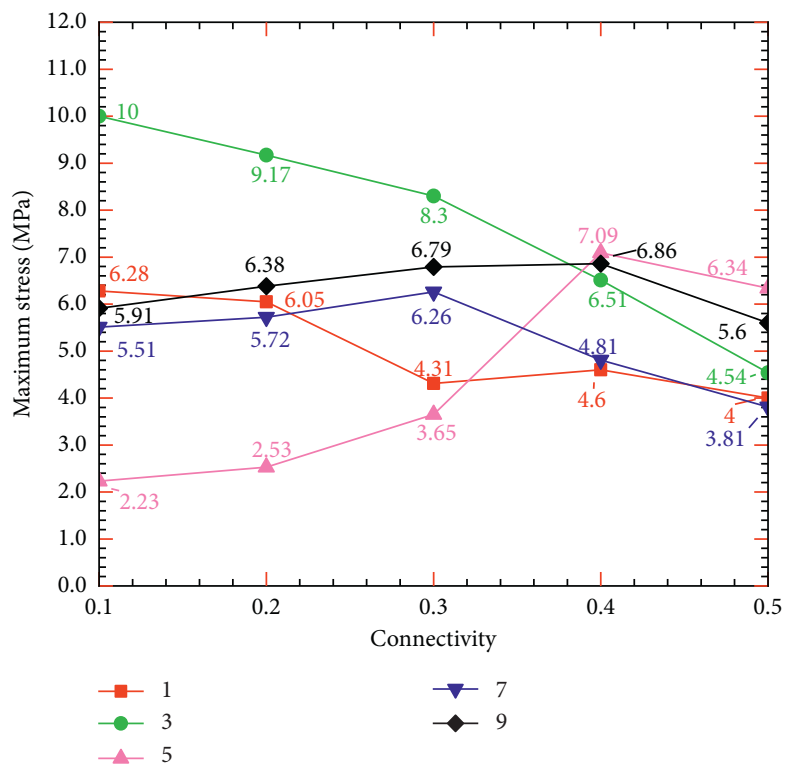

Figure 19: Curves of peak stress of each measurement circle in the third group of specimens.

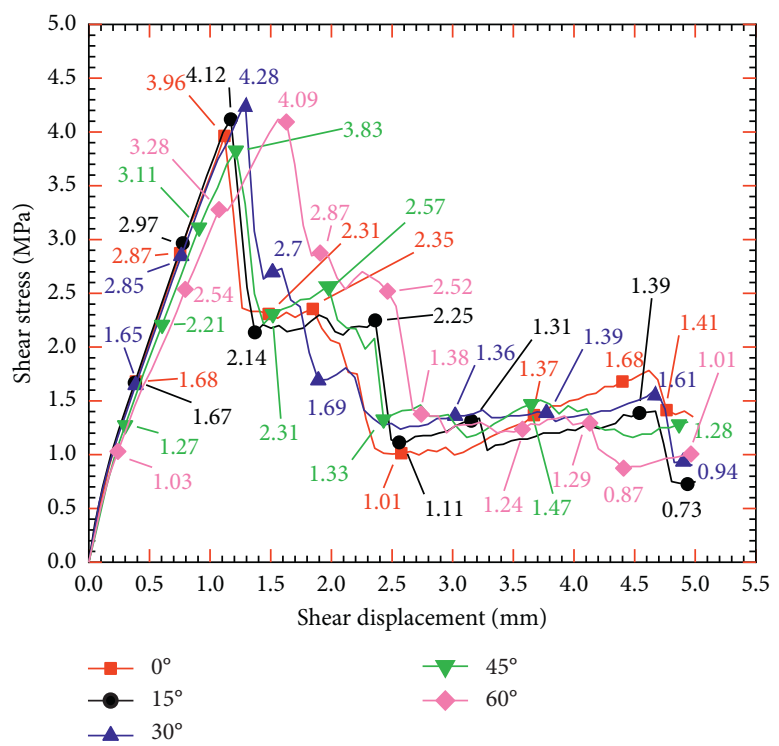

FIGURE 20: The stress-strain curves of NNJRM with different relief angles.

TABLE 12: The peak shear stress of NNJRM with different relief angles.

\begin{tabular}{lccccc}
\hline Relief angle & $0^{\circ}$ & $15^{\circ}$ & $30^{\circ}$ & $45^{\circ}$ & $60^{\circ}$ \\
\hline Peak shear stress (MPa) & 3.96 & 4.12 & 4.28 & 3.83 & 4.09
\end{tabular}

\section{Summary}

In this section, the results of each of the above five tests are summarized separately, and these results of this study are generally consistent with the research conclusions in relevant articles [30, 31, 45-51]. It indicates that the results are reliable. In addition, the influence of the normal stress, shear rate, connectivity of joints, relief angle, and inclination angle of joints on the strength characteristics, crack development state, and the peak shear stress of the five measurement circles in the rock specimens is discussed below:

(1) After the first group of tests, it has been found that normal stress has significant influence on the characteristics of a rock mass. Specifically, the greater the normal stress, the greater the peak stress and residual stress of noncoplanar nonthrough jointed rock mass, and the stronger the shear capacity of the rock mass. Similarly, the larger the normal stress, the more the cracks produced by shear and tension in the rock mass. The peak shear stresses of measurement 


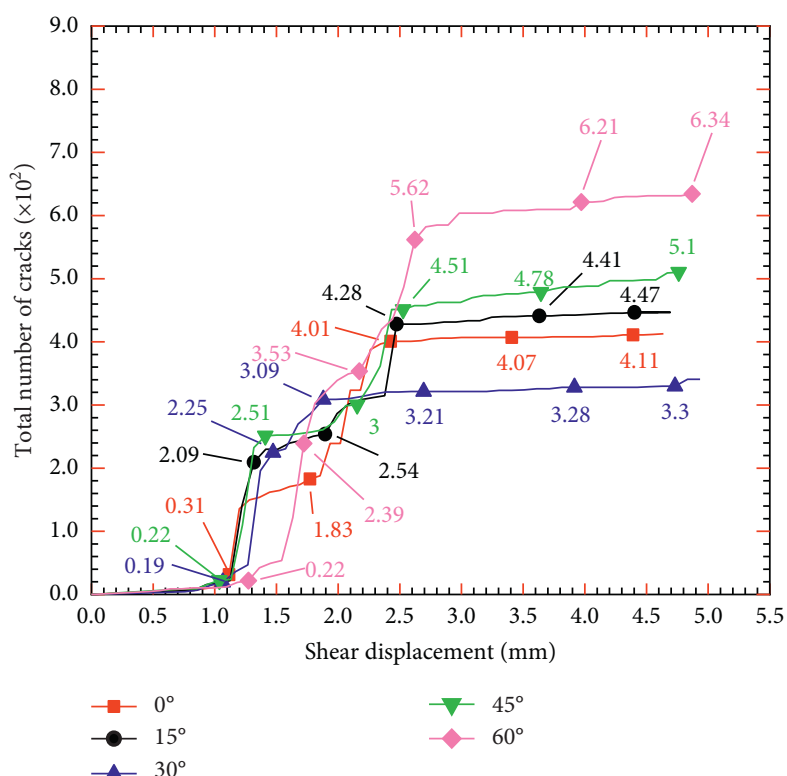

(a)

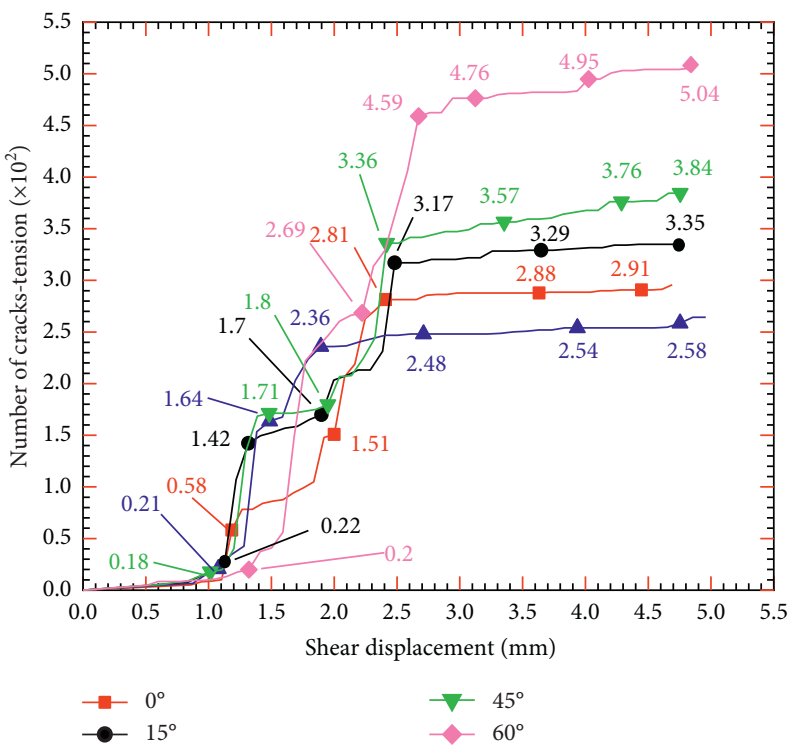

(b)

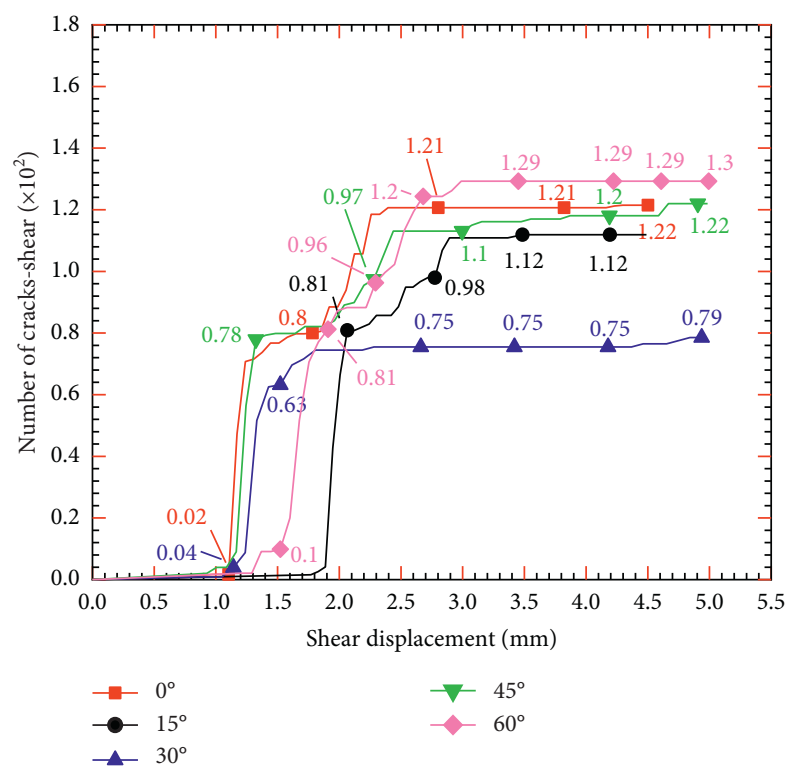

(c)

Figure 21: The number of cracks in the fourth group of specimens. (a) Total number of cracks. (b) The number of cracks caused by tension. (c) The number of cracks caused by shear action.

TABLE 13: The number of cracks generated with different relief angles.

\begin{tabular}{lcccrr}
\hline Relief angle & $0^{\circ}$ & $15^{\circ}$ & $30^{\circ}$ & $45^{\circ}$ & $60^{\circ}$ \\
\hline DFN (strip) & 414 & 447 & 342 & 510 & 634 \\
DFN-t (strip) & 292 & 335 & 263 & 386 & 504 \\
DFN-s (strip) & 122 & 112 & 79 & 124 & 130 \\
\hline
\end{tabular}

circles 1 and 5 in the rock mass are hugely affected by the normal stress, whereas the peak shear stresses of measurement circles 3, 7, and 9 are not significantly affected by the normal stress. In the first group of tests, the rock mass near the center experiences more concentrated stress, especially at the position of the measurement circle 5, which bears the main shear stress. 

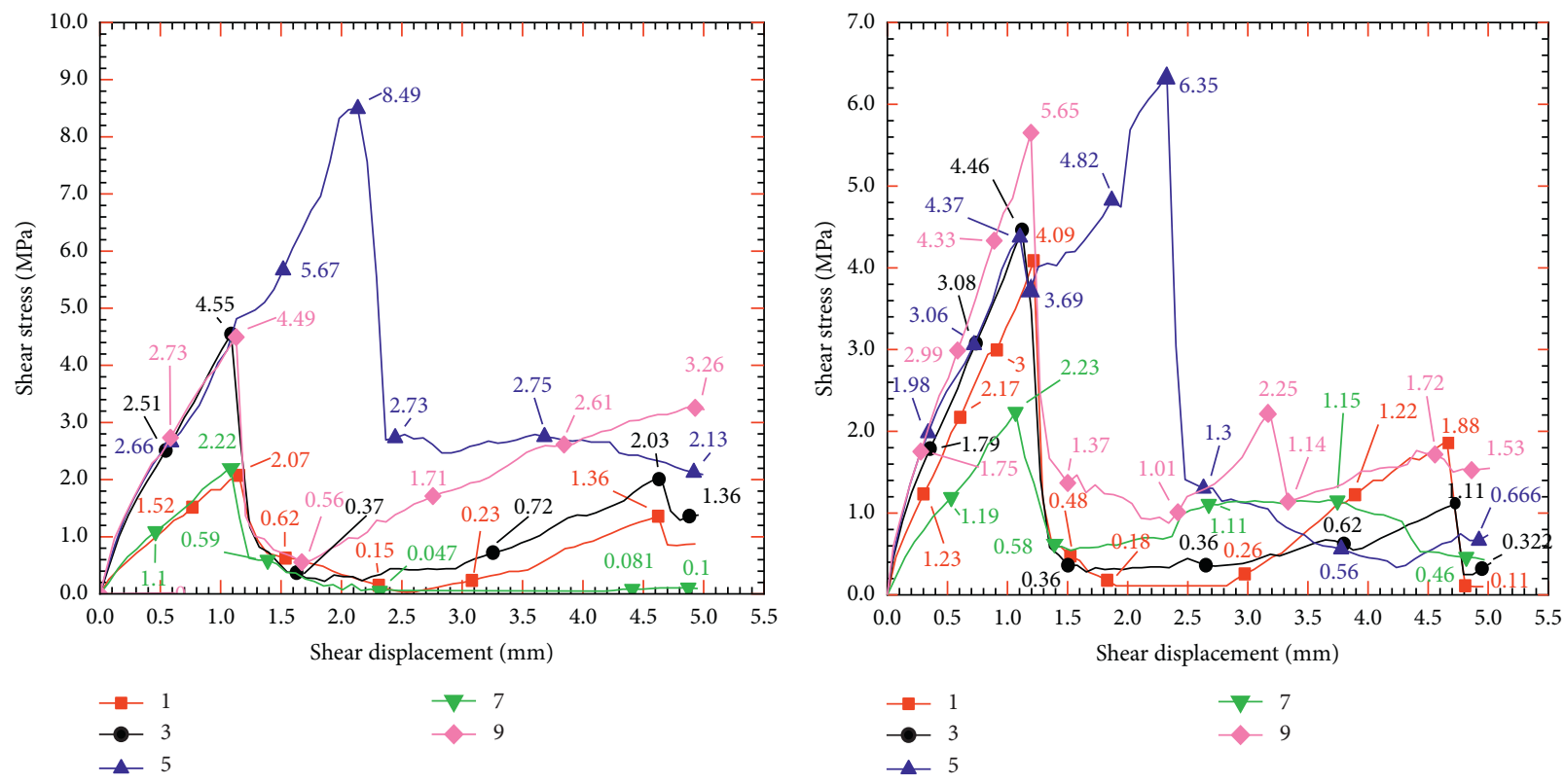

(a)
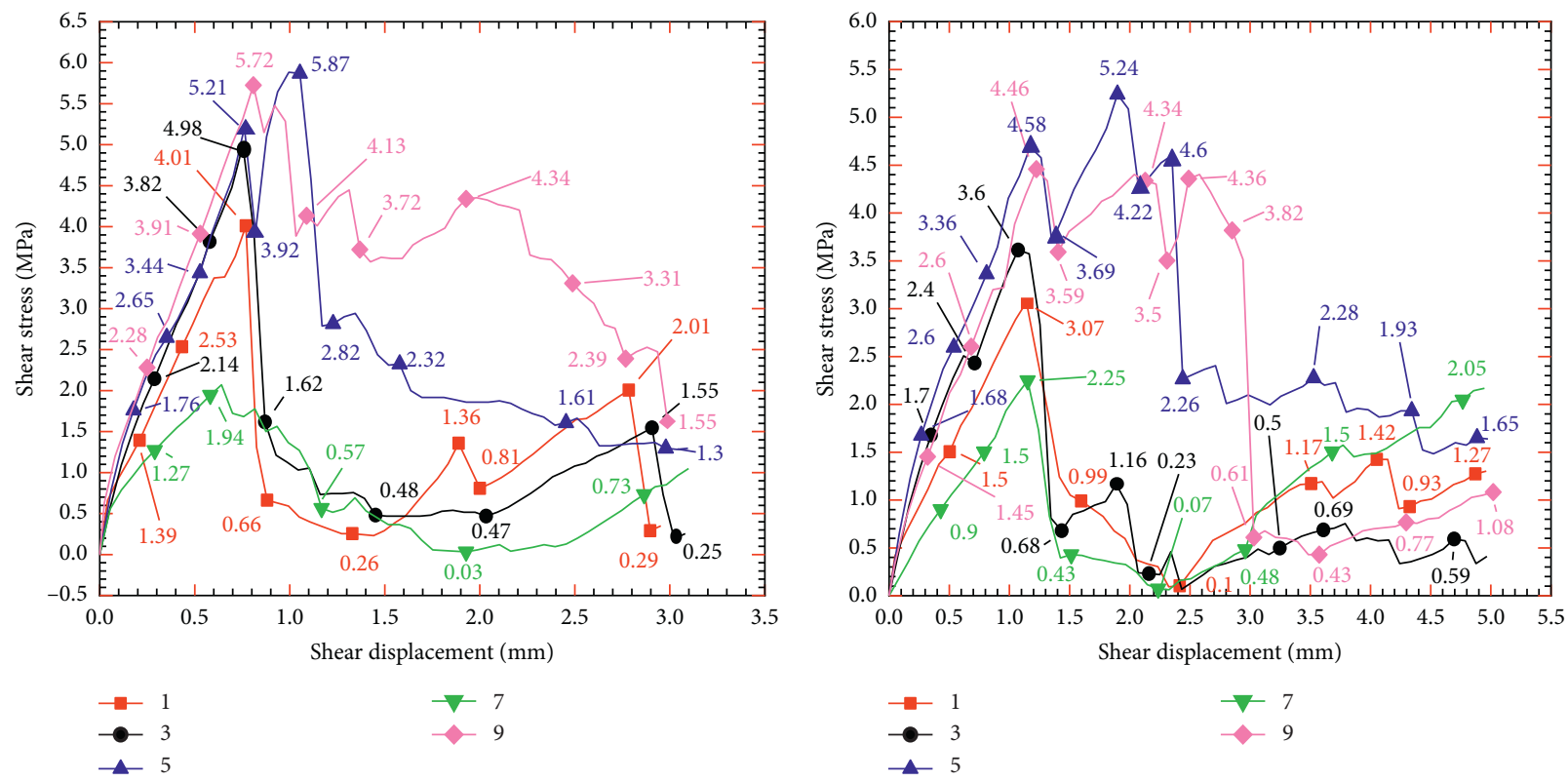

(c)

(d)

FIGURE 22: Continued. 


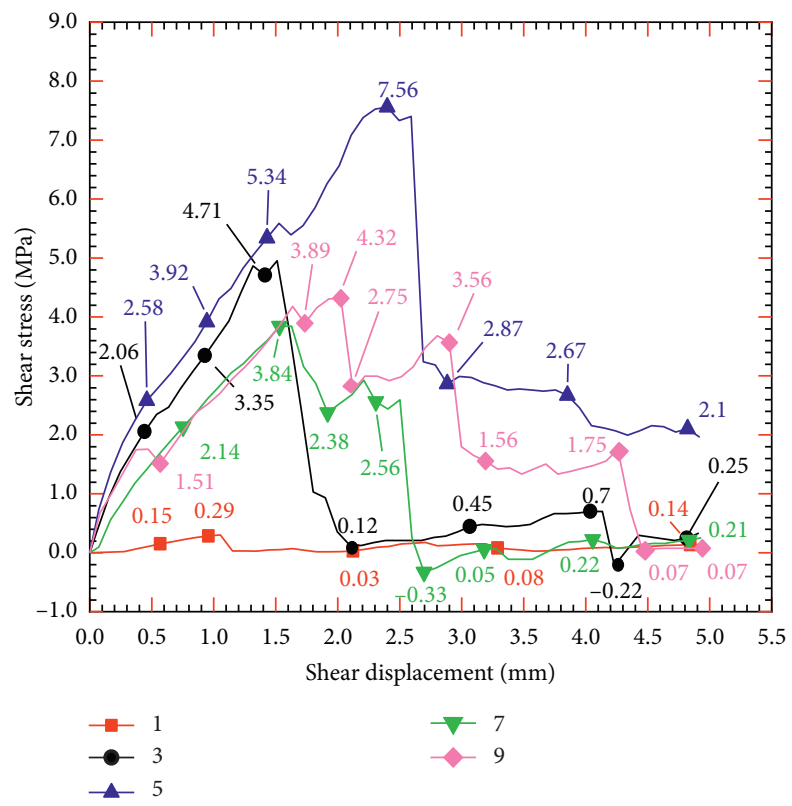

(e)

FIGURE 22: The stress-strain curves of each measurement circle in the fourth group of specimens when the relief angle is (a) $0^{\circ}$, (b) $15^{\circ}$, (c) $30^{\circ}$, (d) $45^{\circ}$, and (e) $60^{\circ}$.

TABLE 14: The peak stress of each measurement circle in the fourth group of specimens.

\begin{tabular}{|c|c|c|c|c|c|}
\hline \multirow{2}{*}{ Number of measuring circles } & \multicolumn{5}{|c|}{ Relief angle } \\
\hline & $0^{\circ}$ & $15^{\circ}$ & $30^{\circ}$ & $45^{\circ}$ & $60^{\circ}$ \\
\hline 1 & 2.07 & 4.09 & 4.01 & 3.07 & 0.29 \\
\hline 3 & 2.55 & 4.46 & 4.98 & 3.6 & 4.71 \\
\hline 5 & 8.49 & 6.35 & 5.87 & 5.24 & 7.56 \\
\hline 7 & 2.22 & 4.37 & 2.04 & 2.25 & 3.84 \\
\hline 9 & 4.49 & 5.65 & 5.72 & 4.46 & 4.32 \\
\hline
\end{tabular}

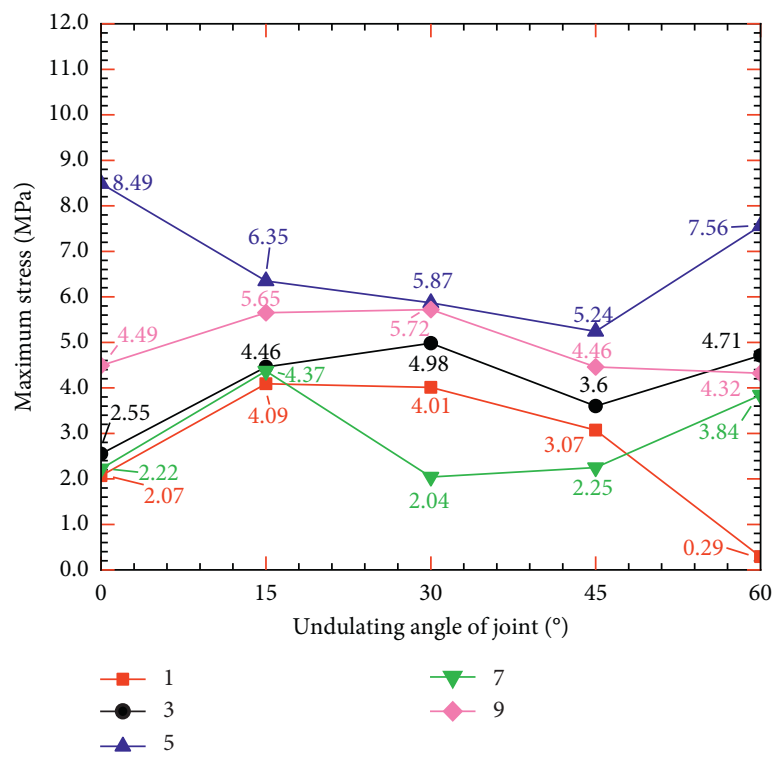

Figure 23: Curves of peak stress of each measurement circle in the fourth group of specimens. 


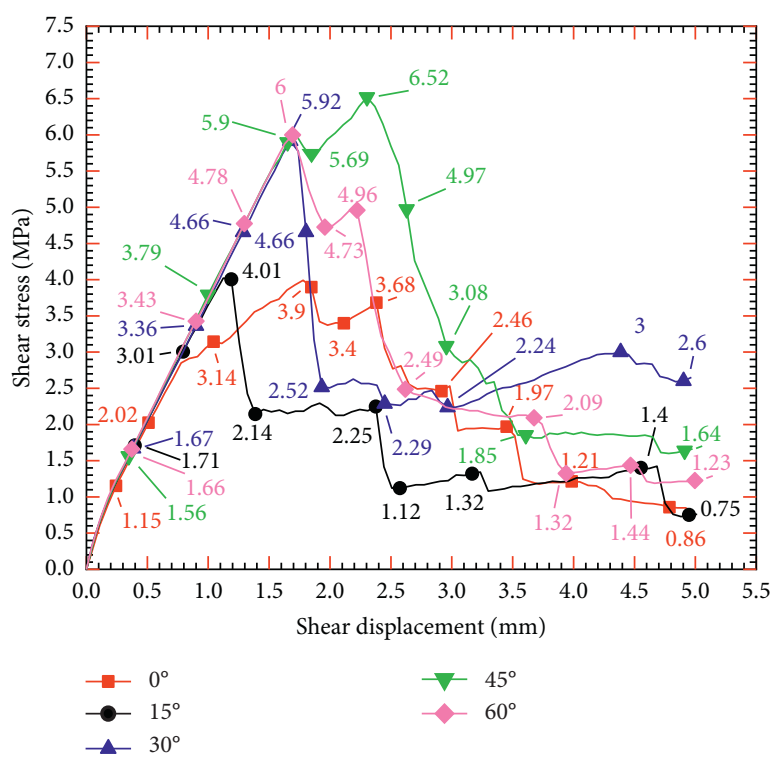

FIgURE 24: The stress-strain curves of NNJRM with different joint inclination angles.

TABLE 15: The peak shear stress of NNJRM with different joint inclination angles.

\begin{tabular}{lccccc}
\hline Joint inclination angle & $0^{\circ}$ & $15^{\circ}$ & $30^{\circ}$ & $45^{\circ}$ & $60^{\circ}$ \\
\hline Peak shear stress $(\mathrm{MPa})$ & 3.95 & 4.01 & 5.92 & 6.52 & 6.00 \\
\hline
\end{tabular}

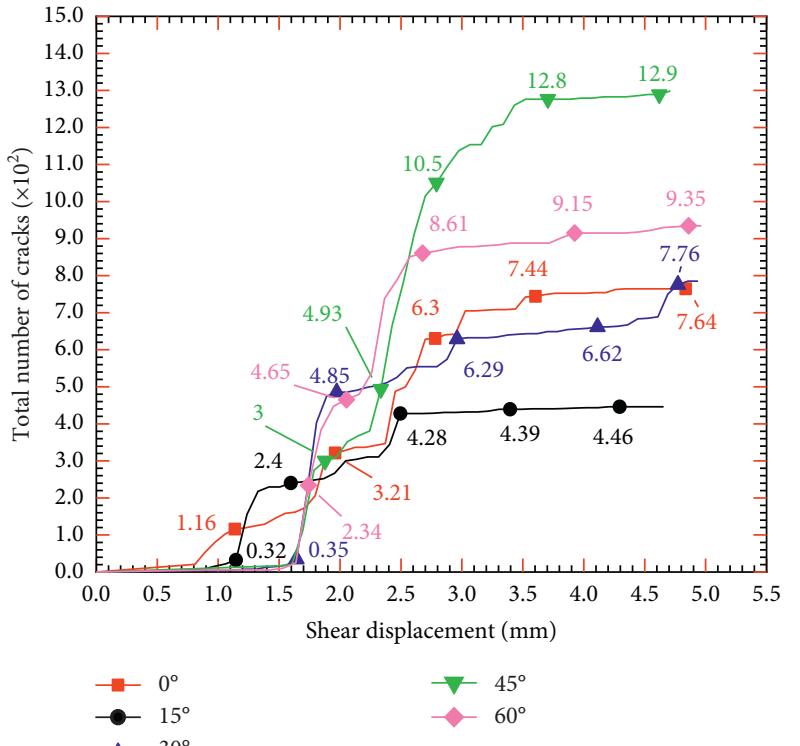

(a)

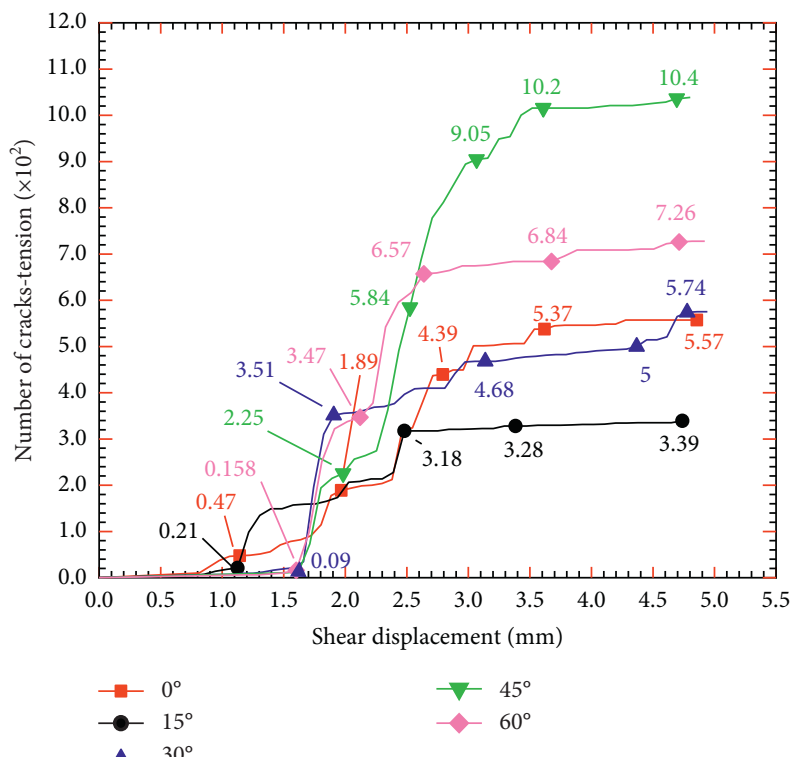

(b)

Figure 25: Continued. 


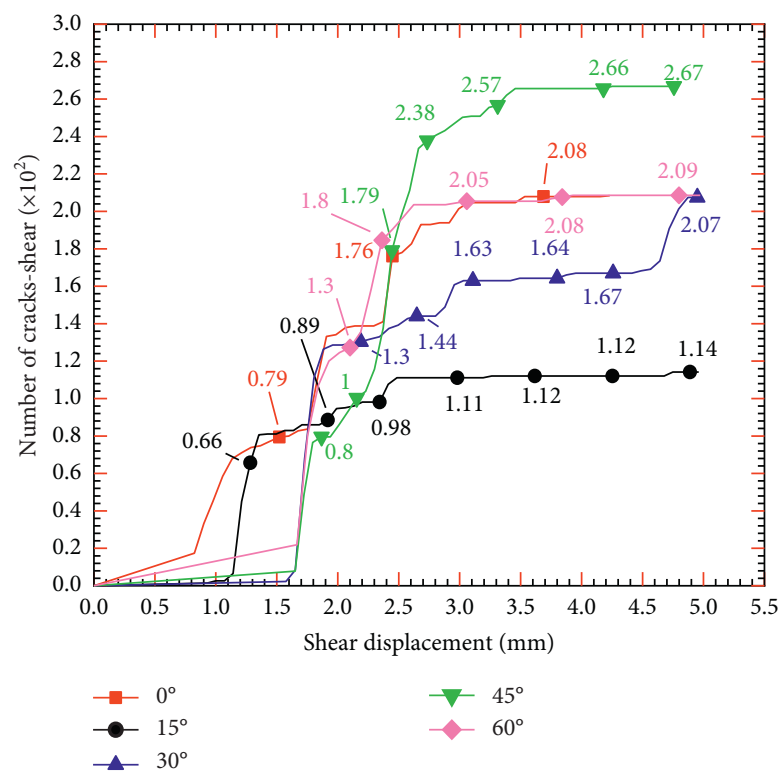

(c)

Figure 25: The number of cracks in the fifth group of specimens. (a) Total number of cracks. (b) The number of cracks caused by tension. (c) The number of cracks caused by shear action.

TABLE 16: The number of cracks generated with different joint inclination angles.

\begin{tabular}{|c|c|c|c|c|c|}
\hline Joint inclination angles & $0^{\circ}$ & $15^{\circ}$ & $30^{\circ}$ & $45^{\circ}$ & $60^{\circ}$ \\
\hline DFN (strip) & 765 & 453 & 781 & 1307 & 935 \\
\hline DFN-t (strip) & 557 & 340 & 574 & 1040 & 726 \\
\hline DFN-s (strip) & 208 & 114 & 207 & 267 & 209 \\
\hline
\end{tabular}

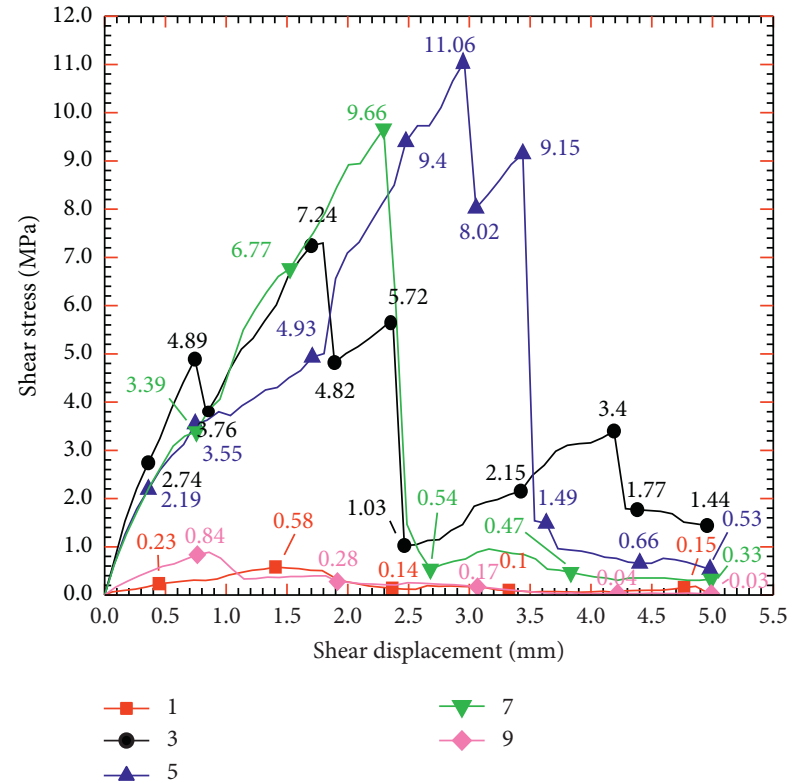

(a)

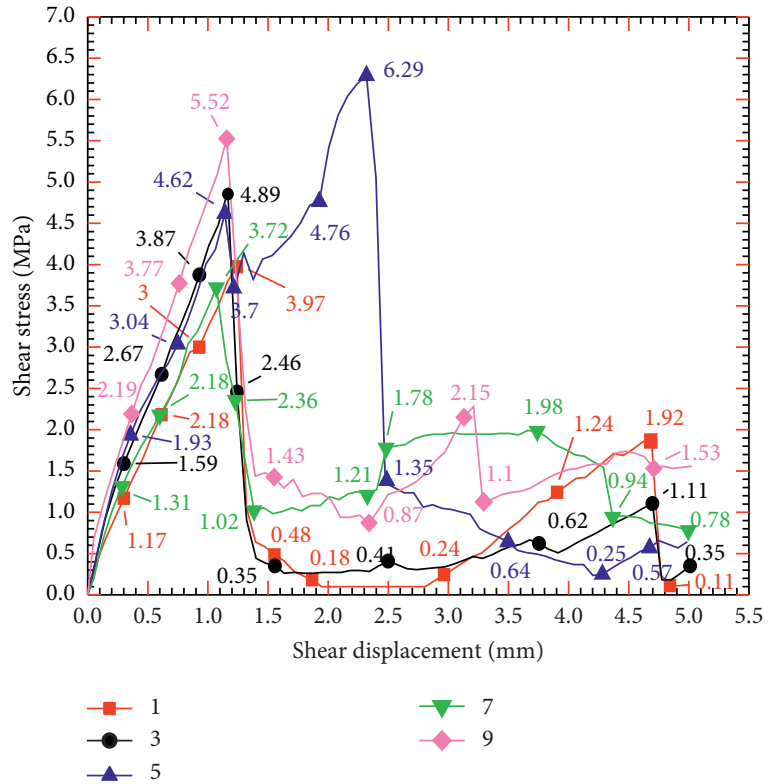

(b)

Figure 26: Continued. 


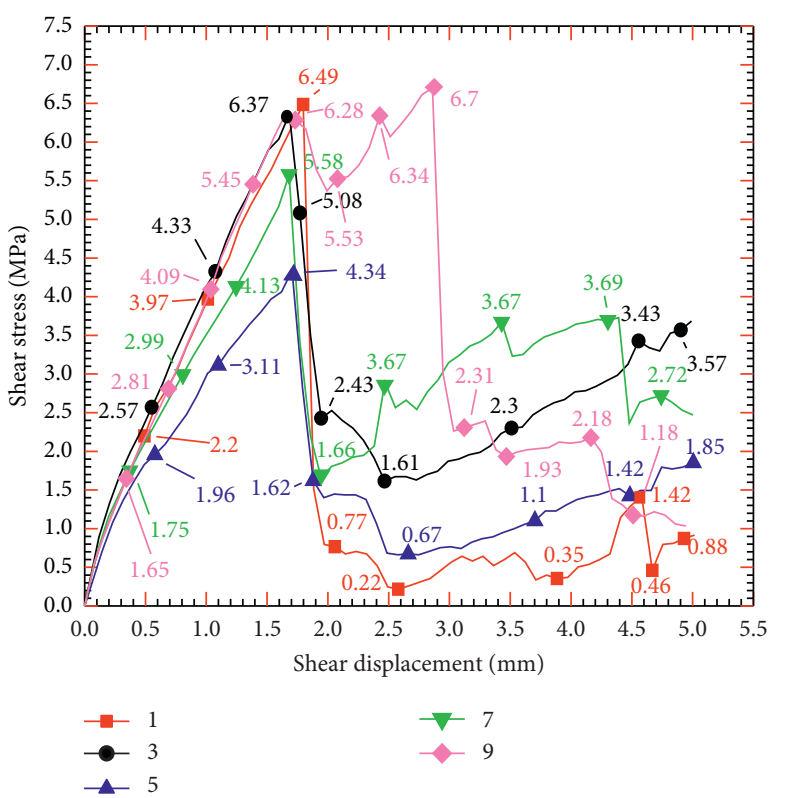

(c)

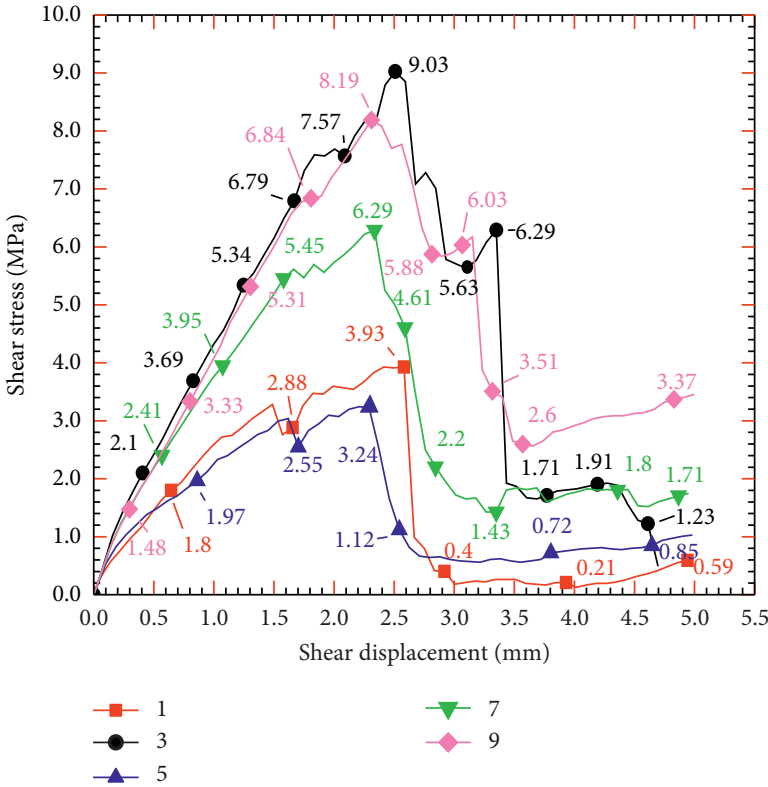

(d)

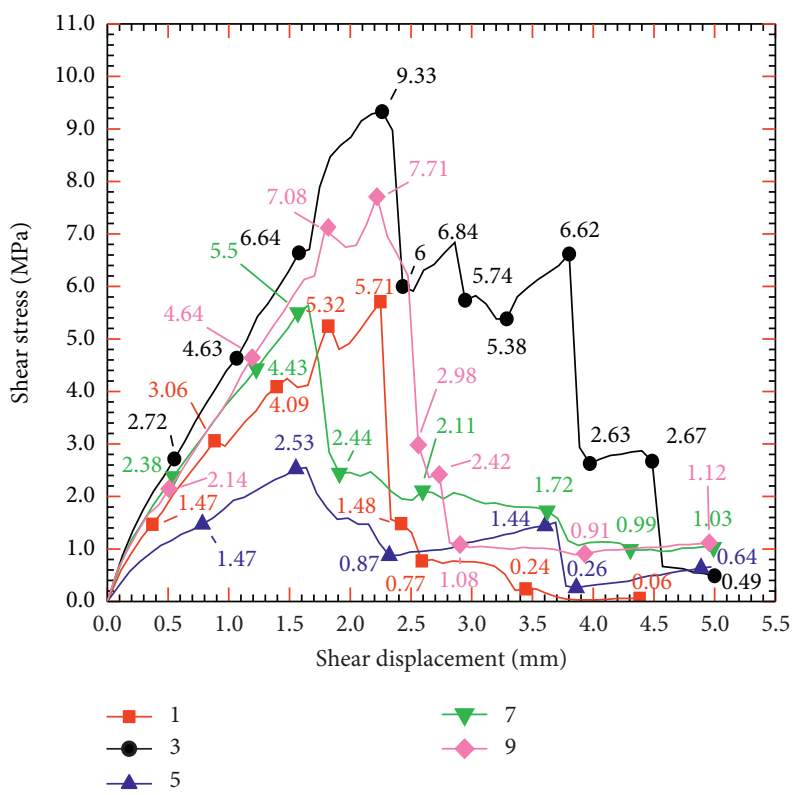

(e)

FIgURE 26: The stress-strain curves of each measurement circle in the fifth group of specimens when the joint inclination angle is (a) $0^{\circ}$, (b) $15^{\circ}$, (c) $30^{\circ}$, (d) $45^{\circ}$, and (e) $60^{\circ}$.

TABLE 17: The peak stress of each circle in the fifth group of specimens.

\begin{tabular}{|c|c|c|c|c|c|}
\hline \multirow{2}{*}{ Number of measuring circles } & \multicolumn{5}{|c|}{ Joint inclination angle } \\
\hline & $0^{\circ}$ & $15^{\circ}$ & $30^{\circ}$ & $45^{\circ}$ & $60^{\circ}$ \\
\hline 1 & 0.58 & 3.97 & 6.49 & 3.93 & 5.71 \\
\hline 3 & 7.26 & 4.89 & 6.37 & 9.03 & 9.33 \\
\hline 5 & 11.06 & 4.62 & 4.34 & 3.24 & 2.53 \\
\hline 7 & 9.66 & 3.72 & 5.58 & 6.27 & 5.53 \\
\hline 9 & 0.84 & 5.52 & 6.70 & 8.19 & 7.71 \\
\hline
\end{tabular}




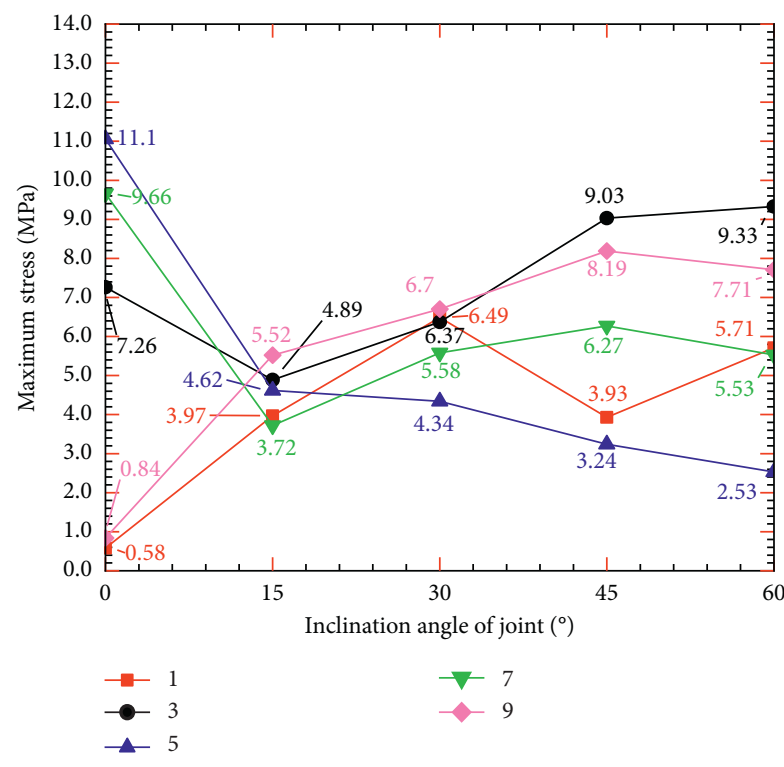

Figure 27: Curves of peak stress of each measurement circle in the fifth group of specimens.

(2) After the second group of tests, it has been determined that both the peak shear stress and shear strength of the rock mass increase with the increase in the shear rate. In addition, with the increase in the shear rate, the number of total cracks, the cracks produced by shear and tension in the rock mass, increases first and then decreases. Moreover, with the increase in the shear rate, the peak shear stress of measurement circle 5 (the measurement circle with the highest peak stress in the rock mass) decreases, the shear stress borne by the central position of rock mass decreases, and so does the shear strength of the central position of the rock specimen. However, since the peak stress of the whole rock mass increases with the increase in the shear rate, the overall shear strength of the rock mass increases. Therefore, it is obvious that the forces within in the rock mass gradually balance with the increase in the shear rate.

(3) After the third group of tests, it has been noted that with the gradual increase in joint connectivity, the peak stress and residual stress of the rock mass decrease and the rock mass resistance to external forces weakens. In addition, the smaller the connection rate of the joints contained in the rock mass, the fewer the cracks generated in the rock mass, the better the integrity of the rock mass, and the stronger the shear resistance of the rock mass. This is consistent with the on-field experience in engineering practice. When the connectivity of joints contained in the rock mass ranges between 0.1 and 0.3 , among the five measurement points, the largest peak shear stress is experienced at measurement circle 3 , while the smallest is experienced at measurement circle 5. Therefore, when the joint connectivity is between 0.1 and 0.3 , the internal stress of the rock mass is distributed close to both sides of the rock mass. When the connectivity of the joints increases to 0.4 or 0.5 , among the five measurement points, the maximum peak stress is experienced at measurement circle 5 in the rock mass, and the peak stresses of the five measured circles are also relatively uniform.

(4) After the fourth group of tests, it has been determined that the peak shear stress, residual stress, the number of total cracks in the rock mass, and the cracks produced by shear and tension in the rock mass show obvious changes with the increase in the joint undulation angle. The peak stress of each measurement circle in the rock mass varies greatly with the change in the joint relief angle. However, a very obvious rule in these changes has not been observed.

(5) After the fifth group of tests, it has been noted that the peak stress of the rock mass increases with the increase in the joint inclination angle. In addition, with the increase in the joint inclination angle, the shear capacity of the noncoplanar nonthrough jointed rock mass increases. Furthermore, the joint inclination angle has significant influence on the generation of the number of cracks in the rock mass. However, the results of this simulation test cannot clearly reveal the precise variation law of the number of cracks. In addition, the peak stresses of the five measurement circles in the rock mass vary significantly with different joint inclination angles. The smallest difference in the peak stresses of the five measuring circles is obtained when the inclination angle is $15^{\circ}$, meaning the stress distribution in the specimen is more uniform.

(6) According to the quantitative relationship between the cracks produced by shear and tension in the rock mass under all the different conditions discussed above, it is proved that the failure of a rock mass in the direct shear test is mainly caused by tension rather than shear action.

\section{Data Availability}

The data used to support the findings of this study are available within this article.

\section{Conflicts of Interest}

The authors declare that they have no conflicts of interest.

\section{Acknowledgments}

This work was supported by the National Natural Science Foundation Project (11562005), the First Class Discipline Construction Project of Civil Engineering in Guizhou Province (QYNYL [2017] 0013), the Natural Science Foundation of Guizhou Province (qkeheji [2019] No. 1057), and Major Scientific and Technological Projects of Guizhou Province (Qiankehe major special project [2018] 3011). 


\section{References}

[1] Y. M. Liu and C. C. Xia, "Weakening mechanism of mechanical behaviors and failure models of rock mass containing discontinuous joints under direct shear condition," Rock and Soil Mechanics, vol. 31, no. 3, pp. 695-701, 2010.

[2] W. Z. Ren, H. Chen, Y. G. Wang, and F. Chen, "Failure mechanism and mechanical characteristics of rockmass containing close intermittent joints under plane stress condition," Key Engineering Materials, vol. 9, pp. 353-358, 2007.

[3] J.-y. Lin, Y.-j. Zuo, J. Wang et al., "Stability analysis of underground surrounding rock mass based on block theory," Journal of Central South University, vol. 27, no. 10, pp. 3040-3052, 2020.

[4] K. Peng, H. Lv, F. Z. Yan, Q. L. Zou, X. Song, and Z. P. Liu, "Effects of temperature on mechanical properties of granite under different fracture modes," Engineering Fracture Mechanics, vol. 226, Article ID 106838, 2020.

[5] K. Peng, J. Zhou, Q. Zou, Y. Zhang, and G. Tan, "Deformation characteristics and failure modes of sandstones under discontinuous multi-level cyclic loads," Powder Technology, vol. 373, pp. 599-613, 2020.

[6] L. X. Xiong, H. J. Chen, T. B. Li, and Y. Zhang, "Uniaxial compressive study on mechanical properties of rock mass considering joint spacing and connectivity rate," Arabian Journal of Geosciences, vol. 12, no. 21, p. 642, 2019.

[7] Z. H. Wang and L. X. Xiong, "Uniaxial compression test of single-joint fractured rock mass considering the influence of thickness and length of joint surface and numerical simulation," Geological Hazards and Environmental Protection, vol. 30, no. 2, pp. 81-85, 2019.

[8] Y. Liu, F. Dai, P. Fan, N. Xu, and L. Dong, "Experimental investigation of the influence of joint geometric configurations on the mechanical properties of intermittent jointed rock models under cyclic uniaxial compression," Rock Mechanics and Rock Engineering, vol. 50, no. 6, pp. 1453-1471, 2017.

[9] M. Liu and E. Liu, "Dynamic mechanical properties of artificial jointed rock samples subjected to cyclic triaxial loading," "International Journal of Rock Mechanics and Mining Sciences, vol. 98, pp. 54-66, 2017.

[10] C. Zhang, C. Pu, R. Cao, T. Jiang, and G. Huang, "The stability and roof-support optimization of roadways passing through unfavorable geological bodies using advanced detection and monitoring methods, among others, in the Sanmenxia Bauxite Mine in China's Henan Province," Bulletin of Engineering Geology and the Environment, vol. 78, no. 7, pp. 5087-5099, 2019.

[11] C. Y. Zhang, Y. X. Wang, H. Ruan, B. Ke, and H. Lin, “The strain characteristics and corresponding model of rock materials under uniaxial cyclic load/unload compression and their deformation and fatigue damage analysis," Archive of Applied Mechanics, vol. 91, pp. 1-16, 2021.

[12] X. S. Li, Z. F. Liu, and S. Yang, "Similar physical modeling of roof stress and subsidence in room and pillar mining of a gently inclined medium-thick phosphate rock," Advances in Civil Engineering, vol. 2021, Article ID 6686981, 17 pages, 2021.

[13] X. S. Li, K. Peng, J. Peng, and D. Hou, "Effect of thermal damage on mechanical behavior of a fine-grained sandstone," Arabian Journal of Geosciences, vol. 14, Article ID 1212, 2021.

[14] X. S. Li, S. Yang, Y. M. Wang et al., "Macro-micro response characteristics of surrounding rock and overlying strata towards the transition from open-pit to underground mining," Geofluids, vol. 2021, Article ID 5582218, 18 pages, 2021.

[15] C. Y. Zhang, Y. X. Wang, and T. T. Jiang, "The propagation mechanism of an oblique straight crack in a rock sample and the effect of osmotic pressure under in-plane biaxial compression," Arabian Journal of Geosciences, vol. 13, no. 15, Article ID 736, 2020.

[16] Y. M. Liu, J. Liu, and C. C. Xia, "Research on strength behavior of rock mass containing discontinuous joints by direct shear test under different joint surface morphologies," Rock and Soil Mechanics, vol. 5, pp. 1269-1274, 2014.

[17] Y. Q. Zhao, J. W. Liu, A. B. Jin, H. Sun, B. X. Wang, and Y. D. Wei, "Study on failure characteristics of intermittent jointed rock mass under loading and unloading condition," Journal of Central South University, vol. 51, no. 7, pp. 18931901, 2020.

[18] M. Bahaaddini, "Effect of boundary condition on the shear behaviour of rock joints in the direct shear test," Rock Mechanics and Rock Engineering, vol. 50, no. 5, pp. 1141-1155, 2017.

[19] M. Bahaaddini, P. C. Hagan, R. Mitra, and B. K. Hebblewhite, "Parametric study of smooth joint parameters on the shear behaviour of rock joints," Rock Mechanics and Rock Engineering, vol. 48, no. 3, pp. 923-940, 2014.

[20] S. Chen and C. Qiao, "Composite damage constitutive model of jointed rock mass considering crack propagation length and joint friction effect," Arabian Journal of Geosciences, vol. 11, no. 11, p. 283, 2018.

[21] Y. M. Liu, Study on Failure Models and Strength of Rockmass Containing Discontinuous Joints in Direct Shear, Tongji University, Shanghai, China, 2007.

[22] M. Bahaaddini, G. Sharrock, and B. K. Hebblewhite, "Numerical investigation of the effect of joint geometrical parameters on the mechanical properties of a non-persistent jointed rock mass under uniaxial compression," Computers and Geotechnics, vol. 49, pp. 206-225, 2013.

[23] B. Wang, Q. H. Jiang, C. Yao, and T. Xie, "Numerical analysis on failure mechanism of intermittent joints," Advanced Materials Research, vol. 255-260, pp. 113-117, 2011.

[24] K. Bian, J. Liu, X. J. Hu, P. C. Li, L. Z. Chen, and Z. P. Liu, "Study on failure mode and dynamic response of rock slope with non-persistent joint under earthquake," Yantu Lixue/ Rock \& Soil Mechanics, vol. 39, no. 8, pp. 3029-3037, 2018.

[25] C. Zhou, M. Karakus, C. Xu, and J. Shen, "A new damage model accounting the effect of joint orientation for the jointed rock mass," Arabian Journal of Geosciences, vol. 13, no. 7, p. 295, 2020.

[26] S. Niu, H. Jing, K. Hu, and D. Yang, "Numerical investigation on the sensitivity of jointed rock mass strength to various factors," Mining Science and Technology, vol. 20, no. 4, pp. 530-534, 2010.

[27] W. G. Cao, X. Tan, C. Zhang, and M. He, "A constitutive model to simulate the full deformation and failure process for rocks considering initial compression and residual strength behaviors," Canadian Geotechnical Journal, vol. 56, no. 5, 2018.

[28] P. Wang, T. Yang, T. Xu, M. Cai, and C. Li, "Numerical analysis on scale effect of elasticity, strength and failure patterns of jointed rock masses," Geosciences Journal, vol. 20, no. 4, pp. 539-549, 2016.

[29] P. Wang, F. Ren, and M. Cai, "Influence of joint geometry and roughness on the multiscale shear behaviour of fractured rock mass using particle flow code," Arabian Journal of Geosciences, vol. 13, no. 4, p. 165, 2020. 
[30] Y. T. Wang and J. Cui, "Direct shear strength characteristics and energy evolution mechanism of discontinuous rock bridge based on PFC2D," Journal of Water Conservancy and Building Engineering, vol. 17, no. 5, pp. 234-238, 2019.

[31] Z. H. Wu, L. An, Z. J. Qi, Y. P. Kou, and B. S. Li, "The numerical simulation method of rock mass blasting based on PFC combined with LS-DYNA," Journal of Mining and Safety Engineering, vol. 38, no. 3, pp. 609-614, 2020.

[32] D. Huang, Y. Li, D. F. Cen, and Q. H. Jiang, "Effect of microscopic crystal grains on strength and fracture behavior of marble under compressive-tensile stress state," Rock and Soil Mechanics, vol. S2, pp. 1-12, 2020.

[33] Q. Z. Chen, Y. M. Liu, A. J. Zhu, and W. Wang, "PFC2Dbased simulative study on influence from non- penetrative heterogeneous joint under various working conditions on mechanical properties of rock mass," Water Resources and Hydropower Engineering, vol. 50, no. 4, pp. 190-199, 2019.

[34] Q. Z. Chen, Y. S. Zhang, Y. M. Liu, W. Wang, and K. Cao, "Influence of joint undulation angle on mechanical properties of non-penetrated joint rock mass," Journal of Underground Space and Engineering, vol. 16, no. 2, pp. 351-358+365, 2020.

[35] Y. Zhou, A. Misra, S. C. Wu, and X. P. Zhang, "Macro- and meso-analyses of rock joint direct shear test using particle flow theory," Journal of Rock Mechanics and Engineering, vol. 31, no. 6, pp. 1245-1256, 2012.

[36] Y. Zhou, G. Han, S. C. Wu, and N. L. Hu, "Meso failure mechanism of rock mass and slope with intermittent joints," Journal of Rock Mechanics and Engineering, vol. 35, no. S2, pp. 3878-3889, 2016.

[37] Y. Zhou, J. F. Chai, and G. Han, "Meso numerical study on the failure mechanism of rock slope with bedding intermittent joints," Engineering Review:Međunarodni Časopis Namijenjen Publiciranju Originalnih Istraživanja S Aspekta Analize Konstrukcija, Materijala I Novih Tehnologija U Području Strojarstva, Brodogradnje, Temeljnih Tehničkih Znanosti, Elektrotehnike, Računarstva I Građevinarstva, University of Rijeka, Rijeka, Croatia, 2017.

[38] X. X. Yang and P. Kulatilake, "PFC3D modeling of a jointed rock block behavior near anunderground excavation and comparison with physical model test results," in Proceedings of the 4th Itasca Symposium on Applied Numerical Modeling, Lima, Perú, March 2016.

[39] M. L. Wang, "Simulation of compression test on gangue by PFC (3D)," Chinese Journal of Rock Mechanics and Engineering, vol. 32, no. 7, pp. 1350-1357, 2013.

[40] X. J. Hu, K. Bian, Y. F. Ge, P. C. Li, and L. Z. Chen, "Failure mode of rock slope with non-persistent joint under static loading based on PFC," Safety and Environmental Engineering, vol. 24, no. 3, pp. 34-42, 2017.

[41] J. Y. Huan, M. M. He, Z. Q. Zhang, and N. Li, "Parametric study of integrity on the mechanical properties of transversely isotropic rock mass using DEM," Bulletin of Engineering Geology and the Environment, vol. 79, 2019.

[42] M. J. Jiang, Y. Sun, H. Chen, J. Y. Yuan, and S. G. Zhang, "DEM numerical simulation of rock masses containing noncoplanar intermittent joints in direct shear test," Journal of Rock Mechanics and Engineering, vol. 34, no. S2, pp. 36673675, 2015.

[43] B. Regassa, N. Xu, and G. Mei, “An equivalent discontinuous modeling method of jointed rock masses for DEM simulation of mining-induced rock movements," International Journal of Rock Mechanics and Mining Sciences, vol. 108, pp. 1-14, 2018.

[44] X. R. Liu, Z. Y. Deng, Y. Q. Liu, Y. M. Lu, S. L. Liu, and Y. F. Han, "Macroscopic and microscopic analysis of particle flow in pre-peak cyclic direct shear test of rock joint," Journal of Coal, vol. 44, no. 7, pp. 2103-2115, 2019.

[45] R. Cao, P. Cao, H. Lin, and X. Fan, "Experimental and numerical study of the failure process and energy mechanisms of rock-like materials containing cross un-persistent joints under uniaxial compression," PLoS One, vol. 12, no. 12, Article ID e0188646, 2017.

[46] A. Ghazvinian, V. Sarfarazi, W. Schubert, and M. Blumel, "A study of the failure mechanism of planar non-persistent open joints using PFC2D," Rock Mechanics and Rock Engineering, vol. 45, no. 5, pp. 677-693, 2012.

[47] L. J. Tao, H. C. Dong, T. Meng, L. Liu, and J. D. Li, "Simulation study of blasting of jointed rock mass using PFC," Blasting, vol. 30, no. 4, pp. 14-19, 2013.

[48] X. Fan, K. Li, H. Lai, Y. Xie, R. Cao, and J. Zheng, "Internal stress distribution and cracking around flaws and openings of rock block under uniaxial compression: a particle mechanics approach," Computers and Geotechnics, vol. 102, pp. 28-38, 2018.

[49] Z. F. Zhang, W. M. Tang, and H. B. Jia, "Particle flow simulation of direct shear test on rock mass containing discontinuous joints with different roughness coefficients," Journal of Changjiang River Scientific Research Institute, vol. 37, no. 266, pp. 130-136, 2020.

[50] Q. Z. Chen, Research on the Extended Penetration Mechanism and Strength of Non-hole-through Jointed Rock Mass, Guizhou University, Guiyang, China, 2019.

[51] F. S. Liu, Y. F. Xue, and J. Yang, "Simulation of particle flow for direct shear test on infilled joint," Water Resources and Hydropower Engineering, vol. 51, no. 557, pp. 163-174, 2020. 